\title{
Impact of Extratropical Cyclone Intensity and Speed on the Extreme Wave Trends in the Atlantic Ocean
}

Carolina Barnez Gramcianinov ( $\square$ carolina.gramcianinov@alumni.usp.br)

Universidade de Sao Paulo https://orcid.org/0000-0002-3919-5226

Ricardo de Camargo

Universidade de Sao Paulo

Ricardo Martins Campos

NOAA Atlantic Oceanographic and Meteorological Laboratory

Carlos Guedes Soares

Centro de Engenharia e Tecnologia Naval e Oceanica

Pedro Leite da Silva Dias

Universidade de Sao Paulo

\section{Research Article}

Keywords: Impact of Extratropical Cyclone Intensity, Speed, Extreme Wave Trends, Atlantic Ocean, winds, ocean surface

Posted Date: October 21st, 2021

DOl: https://doi.org/10.21203/rs.3.rs-995499/v1

License: (c) (i) This work is licensed under a Creative Commons Attribution 4.0 International License.

Read Full License 
Carolina B. Gramcianinov ${ }^{1 *}$, Ricardo de Camargo ${ }^{1}$, Ricardo

${ }^{1}$ Departamento de Ciências Atmosféricas, Instituto de

${ }^{2}$ Cooperative Institute for Marine and Atmospheric Studies, University of Miami, 4600 Rickenbacker Causeway, Miami, 33149,

${ }^{3}$ Atlantic Oceanographic and Meteorological Laboratory, NOAA,

*Corresponding author(s). E-mail(s):

\section{Abstract}

This work analyzes the extratropical cyclone-related extreme waves in the ocean surface and their trends in the North and South Atlantic Oceans. Atmospheric and ocean wave products are obtained from ERA5, 


\section{Introduction}

In the last decades, the demand to access changes on extreme events has been increasing. From an ocean perspective, the study of natural hazards associated with anomalous wind-generated ocean waves (hereafter only waves) is of paramount importance to offshore and coastal activities, with high socioeconomic impacts. Management and maintenance of ships, offshore and coastal structures depend upon knowing the current extreme wave climate and its trends (Bitner-Gregersen et al, 2018; Bernardino et al, 2021). In mid to high latitudes, the main drivers of wave climate are the extratropical cyclones, which are known by their strong winds and large fetch (e.g., da Rocha et al, 2004; Ponce de León and Guedes Soares, 2014, 2015; Campos et al, 2018; Ponce de León and Bettencourt, 2021). In this context, this present study explores the relation between the extreme wave climate and extratropical storm tracks in the Atlantic Ocean, providing a new perspective of the changes in the extreme wave events forced by these atmospheric systems.

One of the challenges regarding wave climate trends studies is that wave distribution cannot be directly related to wind changes. The global wave climate is characterized by large waves in high latitudes, presenting a decrease in significant wave height (swh) towards the equator (Young, 1999). This distribution places the westerly wind belt, which generally indicates the preferred pathway of extratropical cyclones displacement (so-called storm track), as a wave generator in which waves are fully coupled with the overlayer winds (Chen et al, 2002) in a state known as wind-sea. After leaving their generation 
region, these waves can travel far distances and are able to cross ocean basins with low energy attenuation (Alves, 2006; Ardhuin et al, 2009). Such propagating waves are called swell, which combined with the wind-sea results in combined sea states (Guedes Soares, 1984; Vettor and Guedes Soares, 2020). Thus, changes in wave climate are not a straightforward response of the local winds (e.g., Stopa and Cheung, 2014). One solution to evaluate the wind-wave climate relationship would be separating local from remote forcing waves; however, it is not a trivial effort, especially in regions with high influence of swell and wind-sea (Rapizo et al, 2015).

Another problem is the varying range of influence that the cyclone structure (i.e., front positions and movement), displacement speed, and intensity play on the extreme wave occurrence. Even though climate state is a result of the average of weather patterns, changes in the extreme climate must be analysed with more caution regarding special conditions that lead to extreme events. For instance, within the extratropical wind structure, different patterns can generate extreme waves depending on the dominant air-flow. Bell et al (2017) found the influence of both cold and warm conveyor belts in the extreme waves in the Northern Sea while Kita et al (2018) reported extreme waves in distinct portions of the cyclones, such as along the warm front. These studies showed that beyond the climatological pattern, extreme wave studies also need to focus on the characteristics of the generating systems (i.e., the cyclone itself, as well as the sectors with stronger surface winds).

There are several studies about trends and changes of storm tracks in the current climate century (Simmonds and Keay, 2000; Fyfe, 2003; Wang et al, 2006) and future scenarios (e.g., Ulbrich et al, 2009; Catto et al, 2019) but without a direct relation with waves. Globally, the storm track is shifting poleward, resulting in an overall decrease of cyclones at mid-latitudes (e.g., Fyfe, 2003; Geng and Sugi, 2003). However the change signal varies locally, and some regions may present an increase of cyclogenesis, such as the southwest South Atlantic coast, between $35^{\circ} \mathrm{S}$ and $40^{\circ} \mathrm{S}$ (Reboita et al, 2018, 2020). Regarding cyclone intensity, some studies showed the increase in the occurrence of strong cyclones, considering different intensity measurements for both the current climate (Pezza and Ambrizzi, 2003; Reboita et al, 2015) and future scenarios (Geng and Sugi, 2003; Lambert and Fyfe, 2006; Bengtsson et al, 2009). Moreover, Reboita et al (2021) found an increase of $13 \%$ in the occurrence of bomb cyclones in the South Atlantic Ocean, with the worst projected scenario (RCP8.5) presenting deeper, faster and shorter systems. An extratropical cyclone is called an explosive or bomb when it experiences fast deepening over a relatively short time, usually greater than $24 \mathrm{hPa}$ in 24 hours (normalized at $60^{\circ} \mathrm{N}$, Sanders and Gyakum, 1980). A significant positive trend of bomb cyclones in the Southern Hemisphere ( $\mathrm{SH}$ ) was also reported by Lim and Simmonds (2002) analysing the NCEP2 product from 1979 to 1999.

These findings allow a glance at what may happen with wave fields but the extreme wave climate may not be exclusively related to cyclone intensity or storm track location. First, because of the remote partition of the wave 
139 climate, as explained above, and secondly, because some cyclones simply do not

140

141

142

143

144

145

146

147

148

149

150

151

152

153

154

155

156

157

158

159

160

161

162

163

164

165

166

167

168

169

170

171

172

173

174

175

176

177

178

179

180

181

182

183

184 generate extreme waves. Gramcianinov et al (2021b) showed that around $60 \%$ of the extratropical cyclones in ERA5 are associated with swh higher than $5 \mathrm{~m}$ in the Atlantic Ocean. Other factors, such as cyclone displacement speed and fetch orientation, play a big role in extreme wave generation and need to be taken into account in trends and changes studies (Gramcianinov et al, 2021a).

Some recent studies faced difficulties to explain wave trends just by using winds or storm track tendencies. According to Young and Ribal (2019), who evaluated the global trends of wind and waves through three satellite datasets between 1985 and 2018, the wind speed distribution is broadening, with an increase in the mean, mode and percentiles, but this behaviour is not followed by the wave height distribution. The authors found a tendency of higher occurrences of small waves, resulting in a distribution skewed to the left and the increase in $90^{t h}$ percentile waves is confined to the Southern Ocean and North Atlantic Ocean. Moreover, Takbash and Young (2020) found a positive tendency in wave height extremes in the SH, presenting an increase in the centennial swh $\left(\mathrm{swh}_{100}\right)$ of up to $3 \mathrm{~cm} /$ year using ERA5. The Northern Hemispheric trend was negative, but generally not statistically significant. In general most of the studies have shown an increase in wave height extremes in the $\mathrm{SH}$ in the past 41 years and that this is projected to continue in the future (e.g., Dobrynin et al, 2012; Lemos et al, 2019).

The present work applies a cyclone feature-based analysis (Lagrangian) to relate this extratropical system to extreme wave events in the Atlantic Ocean. Each cyclone associated with an extreme event is selected to build a set of statistical analyses regarding the cyclone-wave characteristics. The main goal is to investigate the trends in the cyclone-related waves, building a climatology of these extreme events for the last 42 years. This article is guided by three main questions: (1) What is the distribution of extratropical cyclones that most affect the extreme wave climate in the Atlantic Ocean?; (2) Which are the main characteristics of these cyclone-related waves?; and (3) Are there some significant trends in the storm track and wave events in the last decades?

The document presents a description of datasets and methods used in Section 2, including the key procedures of extreme wave definition and its association with cyclones. Section 3 shows the results, which are discussed in Section 4. Finally, the conclusion and recommendations are made in Section 5.

\section{Data and Methods}

\subsection{ERA5}

ERA5 is the fifth generation of reanalysis from the European Centre for Medium-Range Weather Forecast (ECMWF; Hersbach et al, 2020), produced with the ECMWF's Integrated Forecast System (IFS), version CY41R2, using 4D-Var data assimilation. The atmospheric and wave variables used in this work are on $0.28^{\circ}$ and $0.36^{\circ}$ horizontal grids, respectively. The data were used 
with 1-hourly outputs from 1979 to 2020 and obtained through the Copernicus Climate Change Service (C3S) (2017).

ERA5 presents several improvements regarding its predecessor, the ERAInterim, including development in model physics, core dynamics and data assimilation. Using ASCAT observation as a reference, Belmonte Rivas and Stoffelen (2019) showed that ERA5 surface winds present a $20 \%$ improvement relative to ERA-Interim. Gramcianinov et al (2020a) compared the Atlantic Ocean's storm track characteristics for ERA5 and CFSR/CFSv2 from 1979 to 2019. These authors found that despite both datasets presenting cyclones' climatology in agreement with past studies, the 1-hourly ERA5 produces more continuous track and fewer tracking issues in continental and coastal regions. Considering the wave parameters, Takbash and Young (2020) analysed the magnitude and spatial distribution of mean and extreme wave parameters and found that ERA5 presents a good agreement with estimations from altimeter and buoy data. Further information about the main characteristics of ERA5 and a comparison with ERA-Interim can be found in Hersbach et al (2020).

\subsection{Cyclones dataset}

The cyclone tracks are obtained from the "Atlantic extratropical cyclone tracks database" (AETC) available at Gramcianinov et al (2020b). The AETC uses the TRACK program (Hodges, 1994, 1995, 1999) to identify and track the cyclones, following the method described in Hoskins and Hodges (2002, 2005). A detailed explanation of the method, tracking setup, and evaluation can be found in Gramcianinov et al (2020a), although some relevant details are given in this section. The AETC tracks produced using 1-hourly ERA5 fields are used in this study. CFSR and ERA5 present similar storm track spatial patterns and characteristics, but the use of hourly fields may produce broken tracks to CFSR.

The cyclonic features are identified using the relative vorticity at 850 $\mathrm{hPa}$, which is recommended for the detection of cyclones in middle latitudes (Sinclair, 1994). Mid-latitude strong surface pressure gradient usually masks cyclones, therefore, hindering their detection when using mean sea level pressure (MSLP) fields for the tracking. The target systems are mainly extratropical cyclones, retained by a spectral filter applied during the pre-processing steps. Some subtropical systems can be retained as well, depending on their size. However, in this work, no distinction is made between these two types of systems as the interest is in any cyclone that can generate extreme waves in the extratropical region. AETC includes cyclones that last at least 24 hours, travel further than $1000 \mathrm{~km}$, and pass within the extratropical latitudes of the South Atlantic $\left(85^{\circ} \mathrm{S}-25^{\circ} \mathrm{S}, 75^{\circ} \mathrm{W}-20^{\circ} \mathrm{E}\right)$ and North Atlantic $\left(85^{\circ} \mathrm{N}-25^{\circ} \mathrm{N}\right.$, $\left.65^{\circ} \mathrm{W}-0^{\circ} \mathrm{E}\right)$ at any moment of their lifecycle. 


\subsection{Extreme wave definition}

The definition of an extreme relies on a threshold that can be established either by fixed values or percentiles. In this work, extreme percentiles are used to select wave events by applying a spatial approach adapted from Gramcianinov et al $(2020 \mathrm{c})$. The $90^{t h}, 95^{t h}$, and $99^{t h}$ percentiles are obtained through the distribution of the maximum swh of each event in the time series for each grid point. The definition of a time window is essential to guarantee the independence of each swh peak. To simplify the procedure to use for a large domain a fixed time window is adopted. Several authors used $48 \mathrm{~h}$ (e.g., Caires and Sterl, 2005; Meucci et al, 2020), but to short time windows tend to bias the percentiles in subtropical latitudes since in this location the frequency of systems is smaller. Tests on finding a suitable time window were made, following the autocorrelation method applied by Gramcianinov et al (2020c), resulting in the value of $96 \mathrm{~h}$. In this way, the peaks used for the maximum swh distribution are selected considering a minimal interval of $96 \mathrm{~h}$ between the peaks. The extreme percentiles obtained for the North and South Atlantic basins in the summer and winter can be found in Fig. A1 and A2 of the Supplementary Material.

After selecting the percentiles, the points above the threshold in each time frame are grouped into regions that are afterwards associated with a cyclone track. The centre of mass of each extreme wave region is used in the search and connection with the cyclone centre. The method requires some adaptation from the original one since its application to a larger domain can result in a spurious association between cyclones and extreme waves. Three assumptions are made to restrict the association and to guarantee that the extreme wave is influenced by the local wind, as indicated hereafter.

1. The extreme event is associated with the cyclone that exists at least 1 day before the extreme region. This criterion is important to avoid the association of secondary cyclones to the wave extremes generated by a parental cyclone - considering that waves need a time scale of days to develop even for the highest wind speeds (Hasselmann et al, 1973; Ardhuin and Orfila, 2018).

2. To avoid the inclusion of swell dominated extremes consideration is given to extreme points in which the significant height of wind waves (shww, given by ERA5) corresponds to more than $50 \%$ of the swh. While the swh is calculated using the integral over all two-dimensional wave spectrum, the shww uses only the wind-sea wave spectrum obtained by only considering the components of the two-dimensional wave spectrum that are still under the influence of the local wind. Separating swell from wind-sea is not trivial, especially in a high wave generation environment such as the Southern Ocean (Rapizo et al, 2015), which is partially covered by the present domain. Other approaches, such as establishing a minimum value for the difference between wind and peak wave direction (e.g., $90^{\circ}$ by Rapizo et al, 2015 ) it is not practicable in such a high-resolution grid. Interaction between 
remote propagating and local waves can remain, but focusing on extreme percentiles also helps the exclusion of swell dominated cases.

3. The cyclone centre is associated only if it is within $1500 \mathrm{~km}$ from the centre of mass of the extreme wave region. The cyclone-related waves are then defined in this work as an extreme wave region associated with a local cyclone by the method described above.

\subsection{Cyclone-related wave parameters}

Several cyclone parameters are calculated using the track information provided by the AETC dataset. The maximum 10-m wind speed is added to each track by a general search for the maximum value within a $6^{\circ}$ radius of the cyclone centre (Bengtsson et al, 2009) and is used as a measure of cyclone intensity together with the vorticity. The centre of the cyclone along the track is also used to calculate cyclone displacement and the distance and the relative position between cyclone and extreme wave regions. The entire track information of the cyclone is used to produce the storm track statistics.

Mean parameters of the cyclone-related waves are used to compute statistics, producing distribution maps of mean swh $\left(\mathrm{swh}_{\text {mean }}\right)$, maximum swh $\left(\mathrm{swh}_{\max }\right)$, mean wave direction, mean 10-m wind direction, and others. These parameters are obtained directly from the ERA5 products and the value associated with each case is the average between all points in the extreme regions (i.e., that overpasses the extreme percentile).

Spatial statistics of cyclone-related wave parameters, cyclone genesis and track distribution are computed using the spherical kernel estimator approach (Hodges, 1996). The maps are built using the position of the centre of mass of the extreme wave region while the cyclone spatial statistics uses the centre of the cyclones. The tendencies are calculated through differences between the two 21 years time slices in the whole period and were tested using the Monte Carlo significance test (Hodges, 2008) with 1000 samples of the set of tracks for each period.

The results focus on the winter and summer for each basin once they represent two opposite states in the annual cycle. To the North Atlantic analysis, the boreal summer is defined as June, July, and August (JJA) and the winter as December, January, and February (DJF). To the South Atlantic, the austral summer and winter are defined as DJF and JJA, respectively.

\section{Results}

286

287

288

289

290

291

292

293

294

295

296

297

298

299

300

301

302

303

304

305

306

307

308

309

310

311

312

313

314

\subsection{Extreme wave events}

The cyclone-related extreme wave distribution obtained based on different percentiles is presented in terms of density in Figs. 1 and 2, which may be interpreted as the frequency in which a location (area $=5^{\circ}$ spherical caps) is affected by extreme waves in a month, not distinguishing the same event along the time axis. This means that long events also contribute to high densities. 
(a) DJF | 90th

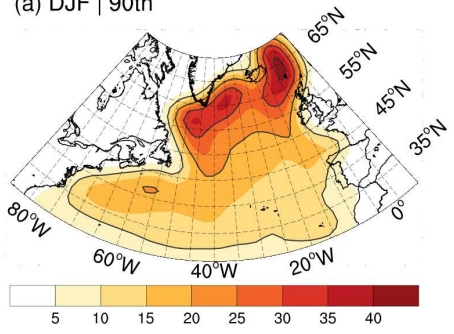

(c) DJF | 95th

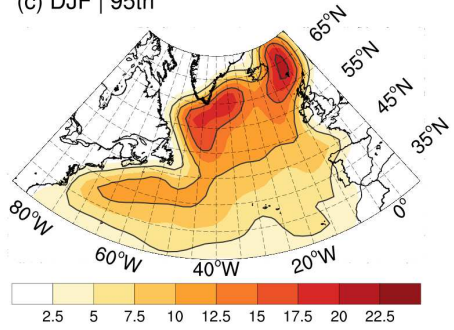

(e) DJF | 99th

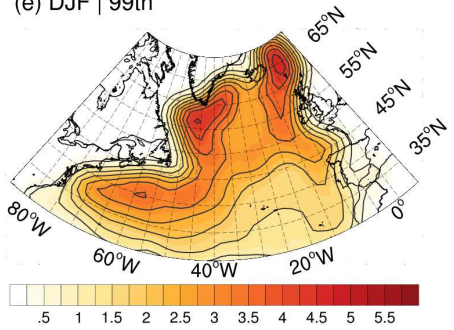

(b) JJA | 90th

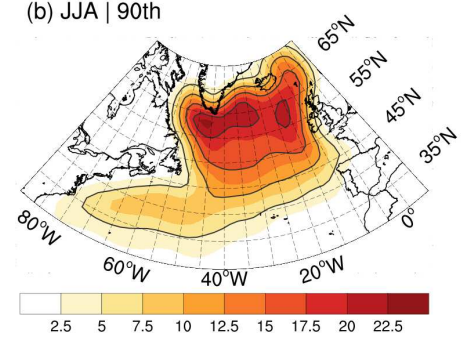

(d) JJA | 95th

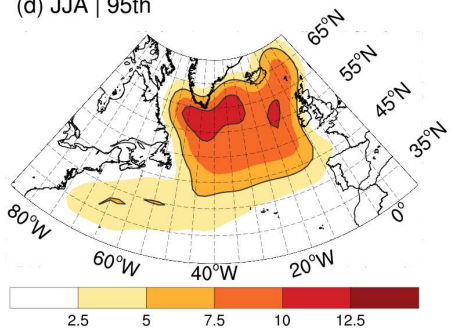

(f) JJA | 99th

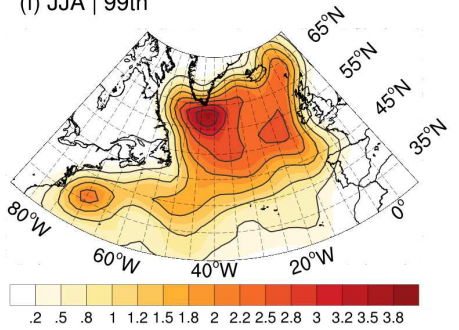

Fig. 1 Density of extreme wave events associated with cyclone (shaded) in the North Atlantic Ocean: in the boreal $(a, c)$ winter (DJF) and (b,d) summer (JJA) for the $(a, b)$ $90^{t h},(\mathrm{c}, \mathrm{d}) 95^{t h}$, and (e,f) $99^{t h}$ percentiles of waves events. Density unit is the occurrence of extreme wave regions per month per area, where the area is $10^{6} \mathrm{~km}^{2}\left(\sim 5^{\circ}\right.$ spherical cap). Density is contoured by the double of coloured level intervals.

In the North Atlantic (Fig. 1), there are three hot spots for extreme wave events located on the northeastern USA coast, south of Greenland, and northwest of the British Islands. The last two regions are highlighted in all percentiles, however, the US coast becomes more evident in more extreme thresholds (Fig. 1c-f), in both seasons. The winter presents higher densities than the summer, especially in the hot spots further north. In the summer, the high density near the British Islands shifts slightly southward.

The South Atlantic presents a more zonal distributed event occurrence (Fig. 2 ), with a high density between $40^{\circ} \mathrm{S}$ and $55^{\circ} \mathrm{S}$ and similar densities range in both seasons, even though the summer presents slightly less event occurrence. The Drake Passage (DKP) and its surroundings, in the eastern boundary of the 
domain, present higher densities in all percentiles for both seasons. However, it is possible to note that the high density shifts southeastward with the increase of the percentile. This region is known for the high waves and bad navigation conditions (e.g., Campos et al, 2020). In the winter, the southwestern South Atlantic (swSA), between $50^{\circ} \mathrm{S}$ and $35^{\circ} \mathrm{S}$ along the South American coast, appears as a hotspot of events, which is more evident in the $99^{\text {th }}$ percentile. In fact, the swSA generally presents higher density than other locations at the same latitude, showing a density distribution skewed to the west, especially in the summer.
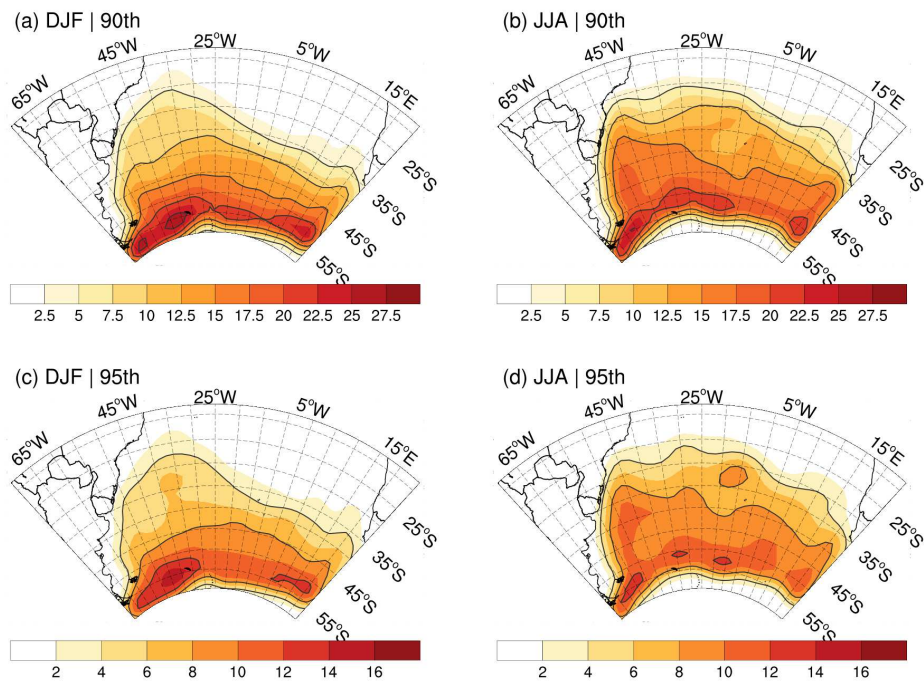

(e) DJF | 99th
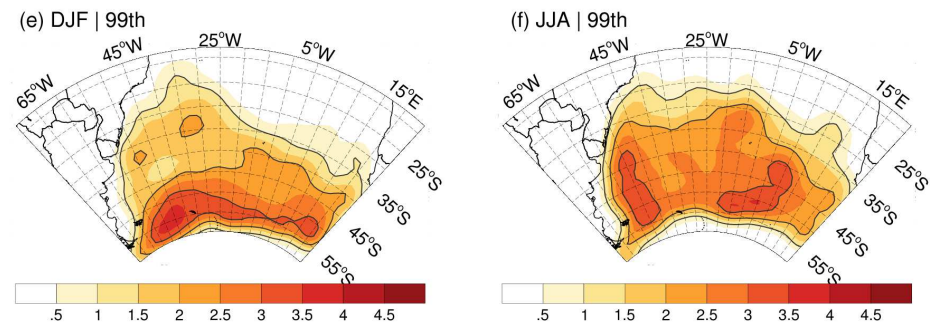

Fig. 2 Density of extreme wave events associated with cyclone (shaded) in the South $90^{t h},(\mathrm{c}, \mathrm{d}) 95^{t h}$, and $(\mathrm{e}, \mathrm{f}) 99^{t h}$ percentiles of waves events. Density unit is the occurrence of extreme wave regions per month per area, where the area is $10^{6} \mathrm{~km}^{2}\left(\sim 5^{\circ}\right.$ spherical cap). Density is contoured by the double of coloured level intervals. 


\subsection{Cyclones associated with extreme waves}

Table 1 presents the annual mean of cyclones associated with extreme waves for each domain, season, and percentile. In the 1979-2020 period, the NA presented 38 and 17.5 cyclones per year related to the $90^{\text {th }}$ percentile wave occurrence, for the boreal winter (DJF) and summer, respectively, which corresponds to $24.4 \%$ and $14.9 \%$ of the cyclones in these seasons. The percentages of wave-associated cyclones follow the reduction of the cyclones in more extreme percentiles, with almost double the cyclones in the winter than in the summer. In the SA, differences between the austral summer (DJF) and winter (JJA) are not so evident. Between 1979 and 2020, the SA presented 32.5 and 39.2 associated cyclones per year for the summer and winter, considering the $90^{\text {th }}$ percentile waves. The percentage of associated cyclones in the summer is slightly larger than in the winter, even though the former presents a lower annual mean.

Table 1 Annual mean of cyclones for the different analyzed periods. The climatology values are for all cyclones in the database and associated cyclones indicate only systems related to extreme waves, according to the percentil used to the selection of the wave regions. The percentage for each percentile is calculated in relation to climatology. Values are presented separately for the North Atlantic (NA) and South Atlantic (SA), as well for the DJF and JJA.

basin \&

season period climatology number of associated cyclones and percentage

$90^{\text {th }} \quad 95^{\text {th }} \quad 99^{\text {th }}$

\begin{tabular}{lccccc}
\hline NA & $1979-2020$ & $156.0 \pm 9.6$ & $38.0 \pm 5.1(24.4 \%)$ & $25.6 \pm 5.1(16.4 \%)$ & $9.7 \pm 3.1(6.2 \%)$ \\
DJF & $1979-1999$ & $156.3 \pm 10.6$ & $37.8 \pm 5.0(24.4 \%)$ & $25.3 \pm 5.0(16.2 \%)$ & $10.0 \pm 2.7(6.4 \%)$ \\
& $2000-2020$ & $156.0 \pm 8.8$ & $38.2 \pm 5.3(24.5 \%)$ & $25.9 \pm 5.2(16.6 \%)$ & $9.4 \pm 3.6(6.0 \%)$ \\
\hline NA & $1979-2020$ & $117.6 \pm 8.2$ & $17.5 \pm 3.4(14.9 \%)$ & $11.2 \pm 2.7(9.5 \%)$ & $4.9 \pm 1.8(4.2 \%)$ \\
JJA & $1979-1999$ & $120.1 \pm 7.1$ & $17.6 \pm 3.1(14.6 \%)$ & $11.0 \pm 2.6(9.1 \%)$ & $4.8 \pm 2.1(4.0 \%)$ \\
& $2000-2020$ & $115.0 \pm 3.7$ & $17.5 \pm 3.7(15.2 \%)$ & $11.4 \pm 2.8(9.9 \%)$ & $5.0 \pm 1.4(4.4 \%)$ \\
\hline SA & $1979-2020$ & $154.0 \pm 9.2$ & $32.5 \pm 6.1(21.1 \%)$ & $21.1 \pm 5.2(13.7 \%)$ & $8.3 \pm 3.0(5.4 \%)$ \\
DJF & $979-1999$ & $151.2 \pm 8.2$ & $29.6 \pm 5.8(19.6 \%)$ & $19.8 \pm 4.8(13.1 \%)$ & $8.1 \pm 2.7(5.4 \%)$ \\
& $2000-2020$ & $156.9 \pm 9.1$ & $35.3 \pm 5.2(22.3 \%)$ & $22.4 \pm 5.3(14.3 \%)$ & $8.5 \pm 3.3(5.4 \%)$ \\
\hline SA & $1979-2020$ & $195.4 \pm 10.9$ & $39.2 \pm 6.0(20.0 \%)$ & $24.4 \pm 4.8(12.5 \%)$ & $9.2 \pm 2.7(4.7 \%)$ \\
JJA & $1979-1999$ & $193.5 \pm 9.6$ & $36.3 \pm 4.8(18.8 \%)$ & $23.4 \pm 4.2(12.1 \%)$ & $9.5 \pm 2.7(4.9 \%)$ \\
& $2000-2020$ & $197.2 \pm 12.1$ & $42.0 \pm 5.8(21.3 \%)$ & $25.4 \pm 5.2(12.9 \%)$ & $8.8 \pm 2.6(4.5 \%)$ \\
\hline
\end{tabular}

Cyclone genesis and track densities computed for the cyclones associated with extreme waves are presented in Fig. 3 and 4 for the North Atlantic and South Atlantic, respectively. In the North Atlantic, the genesis densities show three main genesis regions: lee of the southern Rockies Mountains $\left(35^{\circ} \mathrm{N}\right.$, $\left.102.5^{\circ} \mathrm{W} ; \mathrm{RKM}\right)$, USA northeastern coast $\left(40^{\circ} \mathrm{N}, 75^{\circ} \mathrm{W}, \mathrm{USC}\right)$, and CentralEast Atlantic (centred at $55^{\circ} \mathrm{N}, 30^{\circ} \mathrm{W}, \mathrm{CEA}$ ). North Atlantic storm track climatologies (Dacre and Gray, 2009; Hoskins and Hodges, 2002, 2019) have reported four regions, adding the high occurrence of cyclogenesis on the eastern 
coast of Greenland, which is less relevant to cyclone-related waves according to Fig. 3. The cyclonic activity in the North Atlantic is more intense in the boreal winter (DJF), which reflects in the climatological genesis and track densities distribution. In the winter, the three genesis regions are present while only RKM and USC are relevant during the summer.

Regarding the percentiles, the USC gains even more relevance with the increase of percentile when compared to the other regions. The North Atlantic storm track presents a northeast orientation across the basin (e.g., Hoskins and Hodges, 2002; Gramcianinov et al, 2020a), which is also reproduced by the selected cyclones (Fig. 3). Two regions present high track density and their importance changes according to the season and percentile. During the winter, there is a main storm track along the northeastern USA coast, followed by a secondary branch in the Northeast North Atlantic (NNA). The secondary storm track loses its signal in higher percentiles, indicating that a big part of the cyclones associated with extreme events in the basin comes through the USA coast in this season. The summer has a dispersed and weak storm track but the large densities occur poleward, covering the NNA region.

In the South Atlantic (Fig. 4), the cyclogenesis concentrates along the South American south and central coast, following the three main genesis regions reported by the literature (e.g., Hoskins and Hodges, 2005; Gramcianinov et al, 2019, 2020a). In the austral winter (JJA), the genesis region around $30^{\circ} \mathrm{S}$ in La Plata Basin (LPB) are more active, but the genesis over Argentina (ARG) is usually the largest over the whole year. However, the genesis density in the LPB region overpasses the ARG region in the higher percentiles (Fig. 4d, $\mathrm{f})$. These two genesis regions also appear in the summer densities distribution, with the ARG genesis activity leading in all percentiles. Moreover, in the $90^{t h}$ percentile (Fig. 4a) a genesis density higher than 1 cyclone per season appears covering a region up to $25^{\circ} \mathrm{S}$, along the Southeast Brazilian coast (SBR), which is usually associated with subtropical cyclogenesis and transitions (Gozzo et al, 2014; da Rocha et al, 2019; de Jesus et al, 2020). The track density reflects the genesis density, showing the displacement of the cyclone eastward with a slight tilt poleward, a typical characteristic of the South Atlantic's storm track (Hoskins and Hodges, 2005). However, when comparing to the climatology (Gramcianinov et al, 2020a), it is possible to see that the subtropical path of the storm track is more evident in Fig. 4, due to the large relevance of cyclones generated at LPB and SBR associated with the extreme wave climate.

The intensity and speed distribution of the cyclones associated with extremes are presented as their deviation from the climatology for the same period in Fig. 5. Due to similarity, only the results for the $90^{t h}$ are presented. The cyclones associated with extreme waves are more intense regarding the wind speed at 10-m (Fig. 5a-d). The distribution of this intensification follows the storm track behaviour, reaching lower latitudes in the winter when the cyclone track density is spread. These cyclones are generally slower than climatology as is possible to see by the dominance of negative values in Fig. 5e-g. The speed difference is smaller and can be even positive in the main 
507 storm track position where the upper-level jet is stronger, driving the cyclone

508 propagation.

509

510

511

512

513

514

515

516

517

518

519

520

521

522

523

524

525

526

527

528

529

530

531

532

533

534

535

536

537

538

539

540

541

542

543

544

545

546

547

548

549

550

551

552 (a) DJF | 90th
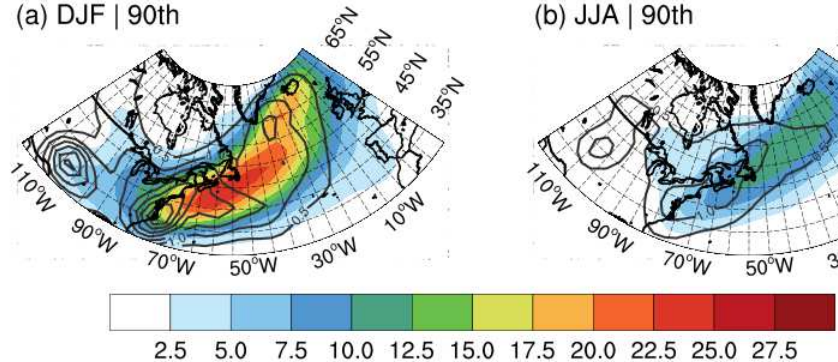

(c) DJF $\mid$ 95th

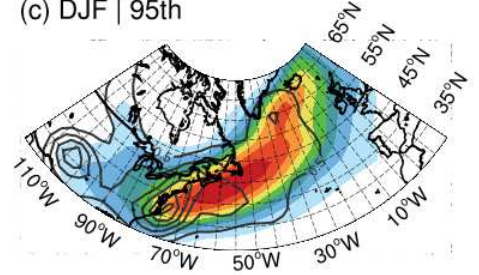

(d) JJA | 95th

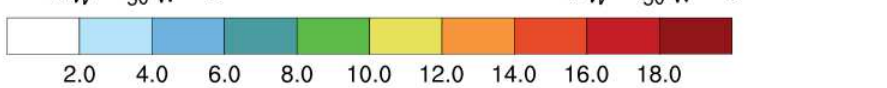

(e) DJF $\mid$ 99th

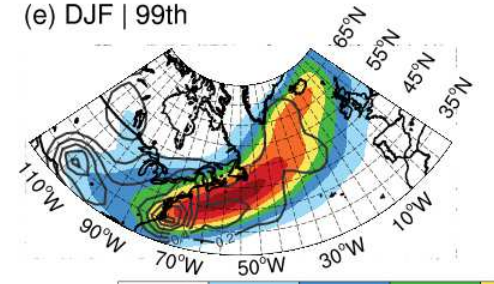

(f) JJA | 99th

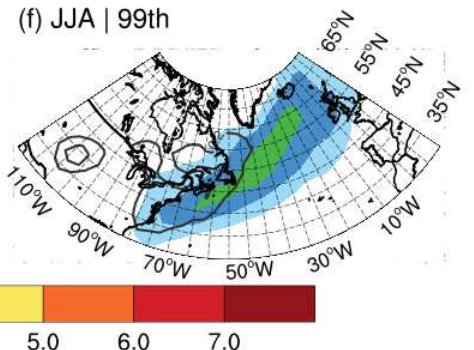

(b) JJA | 90th
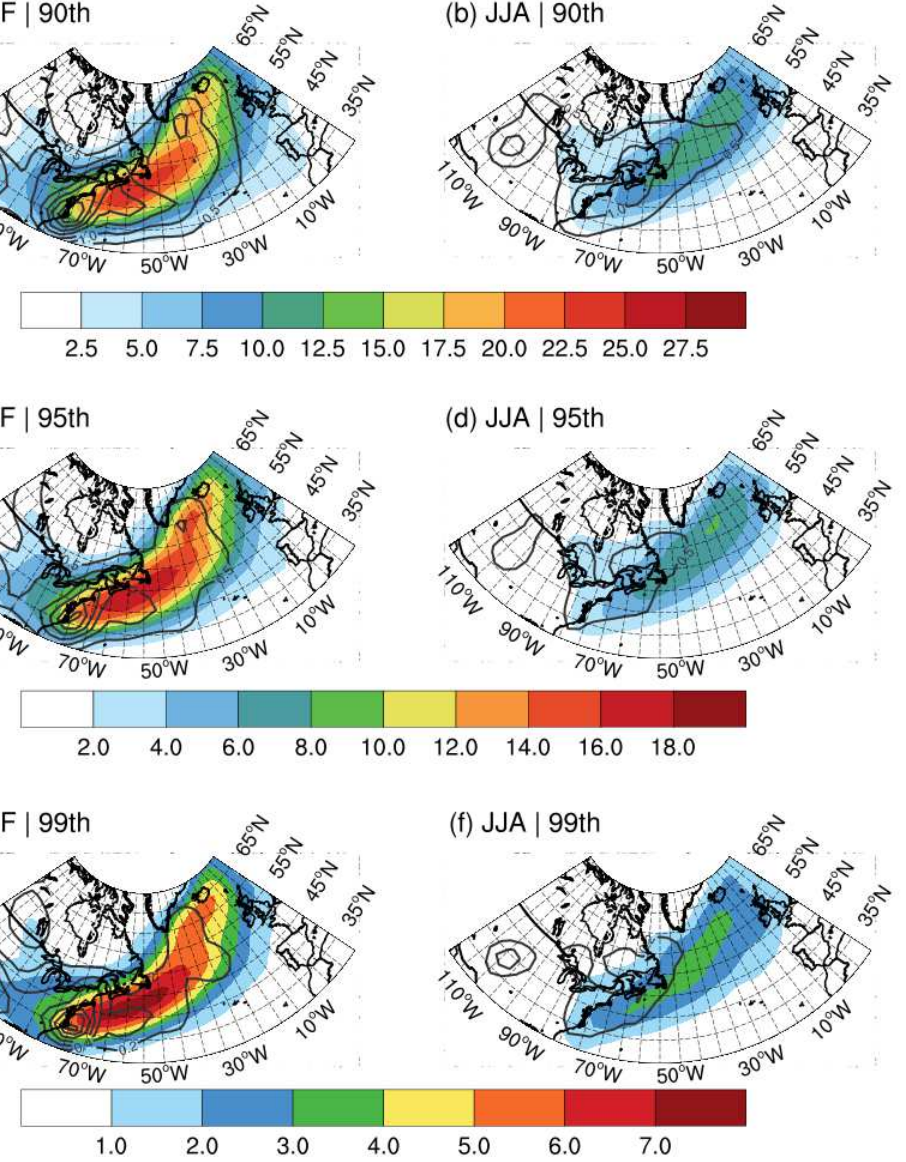

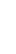

Fig. 3 Cyclone track (shaded) and genesis (contoured) densities associated with extreme waves in the North Atlantic Ocean: in the boreal (a,c,e) winter (DJF) and (b,d,f) summer (JJA) for the $(\mathrm{a}, \mathrm{b}) 90^{t h}$, (c,d) $95^{t h}$, and (c,d) $99^{t h}$ percentiles of waves events. Density unit is cyclone per season per area, where the area is $10^{6} \mathrm{~km}^{2}\left(\sim 5^{\circ}\right.$ spherical cap). Cyclogenesis density is contoured by (a-d) 0.5 and (e,f) 0.2 units.

\subsection{Cyclone-related waves characteristics}

The spatial distributions of cyclone-related waves characteristics were analysed only for the $90^{\text {th }}$ (Fig. 6 and 7) due to the similarity with the other percentiles. Moreover, the $90^{t h}$ percentile was selected because the higher number of cases 
(a) DJF | 90th

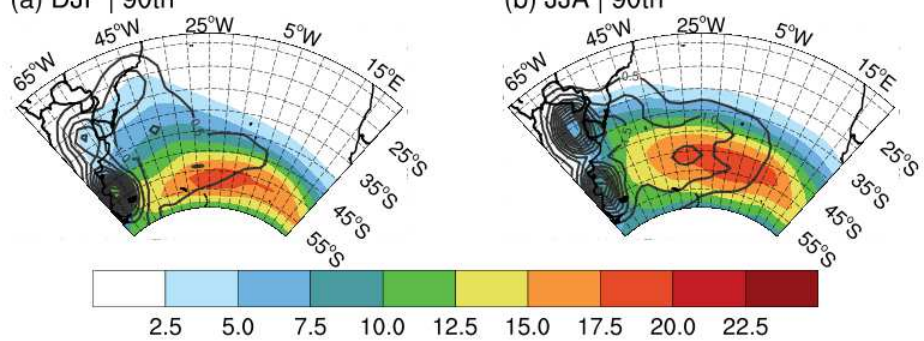

(c) DJF | 95th

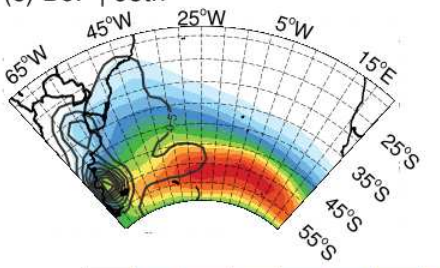

(d) JJA | 95th
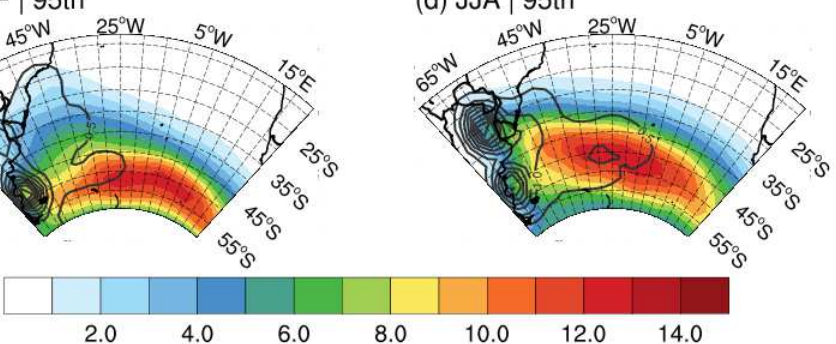

(e) DJF | 99th

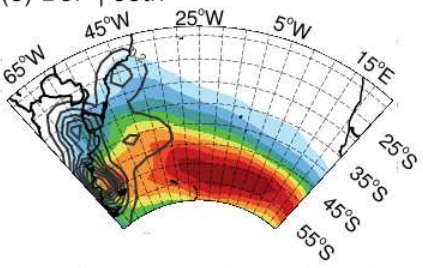

(f) JJA | 99th
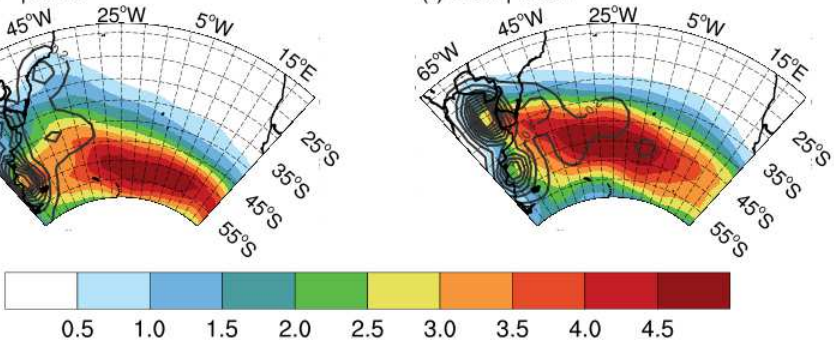

is
553

554

555

556

557

558

559

560

561

562

563

564

565

566

567

568

569

570

571

572

573

574

575

576

577

578

579

580

581

582

583

584

585

586

587

588

589

590

591

592

593

594

595

596 

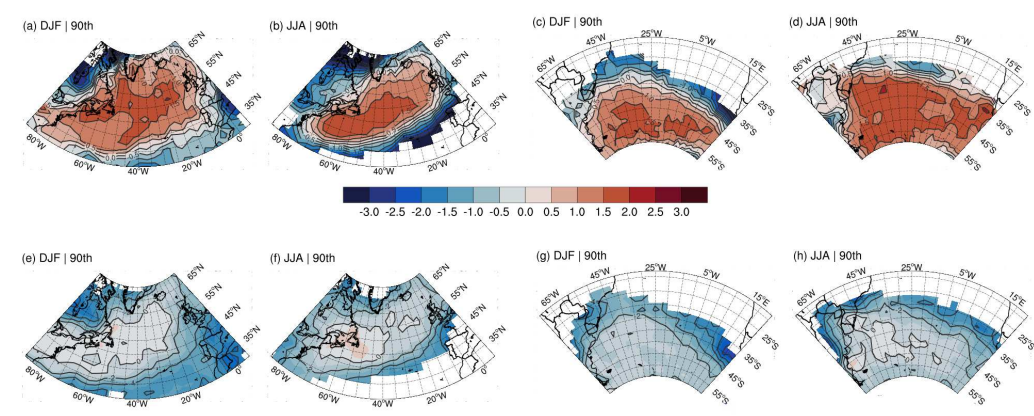

Fig. 5 Differences between cyclone climatology and cyclones associated with extreme waves regarding their $(\mathrm{a}-\mathrm{d})$ maximum $10-\mathrm{m}$ winds $(\mathrm{m} / \mathrm{s})$ and $(\mathrm{e}-\mathrm{h})$ displacement speed $(\mathrm{m} / \mathrm{s})$ in the NA (left) and SA (right).

in the middle-east side of the domains, overlapping the downwind of the storm track (Ponce de León and Bettencourt, 2021).

The mean wave direction of the events (Fig. 7a-d) presents a prevalence of $\mathrm{W}\left(240^{\circ}-300^{\circ}\right)$ and $\mathrm{SW}\left(210^{\circ}-240^{\circ}\right)$ waves in the major part of the NA and SA. In the NA (Fig. 7a, b), extreme events with mean wave direction from $\mathrm{S}$ $\left(150^{\circ}-210^{\circ}\right)$, SE $\left(120^{\circ}-150^{\circ}\right)$, and E $\left(60^{\circ}-120^{\circ}\right)$ occur in the USC and Greenland's surroundings, especially in the summer (JJA). Around $35^{\circ} \mathrm{N}$, near the Portuguese and North Africa coast, the cyclone-related mean wave direction changes from $\mathrm{W}$ in the winter (DJF) to $\mathrm{S}$ and $\mathrm{SE}$ in the summer (JJA). Seasonal variability of the mean wave direction of the cases is also observed in the SA (Fig. 7c,d), where it is possible to find extreme waves propagating from $\mathrm{S}$ and SW in the Argentina, Uruguay, and Southern Brazil coasts and SE and E in the SBR. The mean 10-m wind direction distributions associated with the cyclone-related waves present the same pattern and can be found in Fig. A3 of the Supplementary Material.

Regarding the cyclone sector where the wave extreme occurs (Fig. 7e-h), one can observe that in the NA, most of the events in mid-latitudes occur in the $\mathrm{S}, \mathrm{SW}$ sector of the cyclone, in agreement with the dominant wave and wind mean direction (Fig. 7e,f). In mature and early-occlusion stages, typical of the mid-Atlantic and NNA storm track, this sector of the cyclone is dominated by the cold conveyor belt, located behind the cold front. In the SA (Fig. 7g, h), the analogous situation is observed with the wave extremes occurring mainly in the W and NW sector of the cyclone. However, a comment may be made in the SBR region during the summer (DJF), where the extreme events occur mainly in the E sector of the cyclone with the mean wave direction from $\mathrm{E}$ and SE, which indicate the influence of the warm conveyor belt in this location, as observed by Gramcianinov et al (2020c). Along the Southern Brazilian coast, but in winter, the dominant sector is $\mathrm{W} / \mathrm{NW}$, with the mean wave direction and $10-\mathrm{m}$ wind direction from $\mathrm{S}$ and $\mathrm{SW}$, in agreement with Gramcianinov et al (2021a). According to these authors, yet during the winter, there is a 
prevalence of the cold conveyor belt in early to mature-stage cyclones, and the extreme waves occurred in the downwind of the cyclone fetch along the coast.
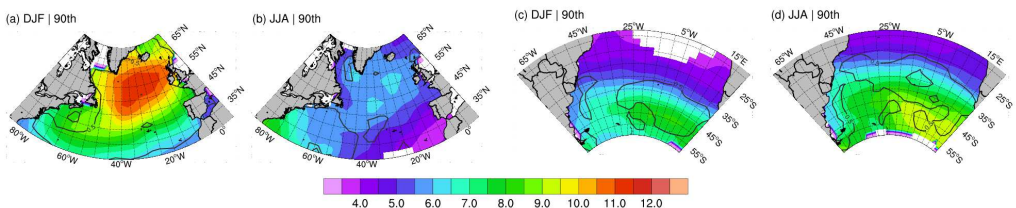

649

650

651

\begin{tabular}{llllllll|l|l|l|}
\hline 4.0 & 5.0 & 6.0 & 7.0 & 8.0 & 9.0 & 10.0 & 11.0 & 12.0
\end{tabular}

652

653
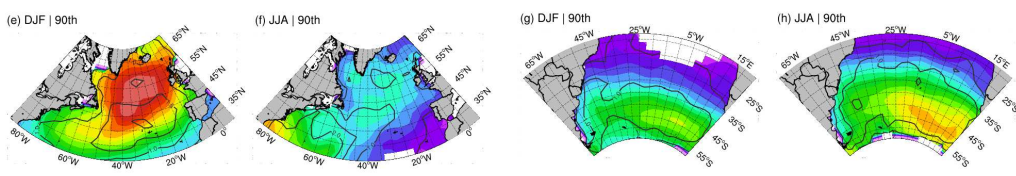

654

655

656

657

658

Fig. 6 Distribution maps of (a-d) mean and (e-h) maximum swh (m) of the $90^{t h}$ percentile cyclone-related waves for the NA and SA in the (a,c,e,g) DJF and (b,d,f,h) JJA. The contour lines are the standard deviation in 0.5 intervals.
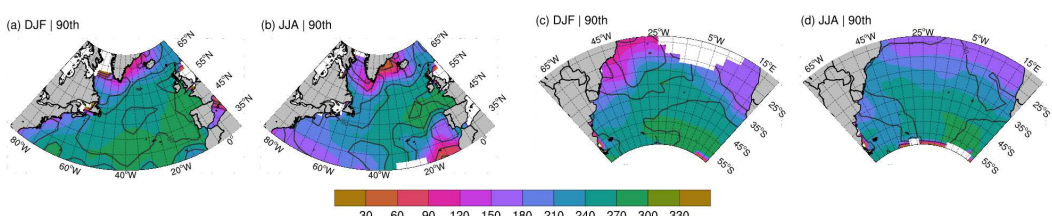

664

665

666

667

668

$\begin{array}{lllllllllll}30 & 60 & 90 & 120 & 150 & 180 & 210 & 240 & 270 & 300 & 330\end{array}$
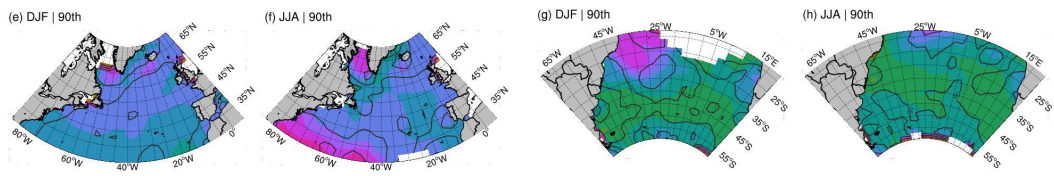

670

671

672

673

674

Fig. 7 Distribution maps of (a-d) mean wave direction of the cases and (e-h) cyclone sectc where the extreme wave occurred (relative to the center of the cyclone). The contour lines are the standard deviation in $30^{\circ}$ intervals. The NA (left) and SA (right) maps are presented in the $(\mathrm{a}, \mathrm{c}, \mathrm{e}, \mathrm{g}) \mathrm{DJF}$ and $(\mathrm{b}, \mathrm{d}, \mathrm{f}, \mathrm{h}) \mathrm{JJA}$ considering $90^{t h}$ percentile cyclone-related waves.

\subsection{Changes in 42 years of reanalysis}

Considering the annual means presented in Table 1 for the two 21-yr time slices, it is noticeable a slight increase or decrease in cyclone number associated with extreme waves, depending on the season. However, the changes are not significant compared to the standard deviation of the annual mean. NA presents an increase in the associated cyclones in the boreal winter (DJF) in the $90^{t h}$ and $95^{t h}$ percentiles, but a decrease in the $99^{t h}$. In the summer (JJA) the increase occurs in the $95^{t h}$ and $99^{t h}$ percentiles. In the austral winter (JJA), SA also presents an increase in the cyclones associated with the $90^{\text {th }}$ and $95^{\text {th }}$ percentiles waves, with a decrease in the higher percentile. However, 
691 in the summer (DJF) there is a general increase of associated cyclones in all 692 percentiles for the SA.

693 Figures 8 and 9 present the trends in the cyclone-related wave occurrence, 694 representing the changes between the two 21-yr time slices, for the NA and 695 SA. The tendency of the $99^{t h}$ percentile is not presented due to the lack of 696 statistical confidence, as explained in the last section. In general, the trends 697 are very heterogeneous within the domains and between summer and winter.

698 Moreover, although the signal pattern is mostly similar between the extreme percentiles, its relative importance varies depending on the percentile.

700 North Atlantic winter tendencies (DJF, Fig. 8a, c) show a decrease in the 701 occurrence of extreme cyclone-related wave occurrence in the NNA, northward 702 of Ireland and British Island. The region of high occurrence south of Greenland 703 (Fig. 1) presents an eastward shift, with the events affecting more the eastern 704 coast of the country. Offshore of the northeastern coast of the USA there is 705 an increase in the occurrence of these events. There is also a slight increase of 706 events in a band that overlaps North of Spain and Portugal but only in the $70790^{t h}$ percentile. The $95^{\text {th }}$ cyclone-related wave occurrence presents a decrease 708 in this region. A very different pattern can be found in the summer (JJA, 709 Fig. 8b,d), where an increase in the occurrence of events over the NNA is 710 noted, covering not only the north but also the west sea offshore Ireland and 711 British Island. The eastward shift of the occurrence hot-spot in Greenland is 712 also observed, as well in the north of Spain. For the summer, there is a weak decrease of events on the northeastern USA coast.

Relative changes in the occurrence of cyclone-related waves are smaller in the SA, but interesting patterns can be observed. In the summer (DJF, Fig.

716 9a,c) most of the domain presents an increase in the occurrence of events, 717 highlighting the region offshore South American coast, from $50^{\circ} \mathrm{S}$ to $20^{\circ} \mathrm{S}$, the 718 region nearby Drake Passage, and between $45^{\circ} \mathrm{S}$ and $55^{\circ} \mathrm{S}$ in the southeast of

719 SA. The South African coast presents a small but significant decrease in event 720 densities. For the winter (JJA, 9b, d) changes, there is still an increase in the 721 South American coast, but from $50^{\circ} \mathrm{S}$ to $40^{\circ} \mathrm{S}$ and only for the $90^{\text {th }}$ percentile.

722 Between $40^{\circ} \mathrm{S}$ and $20^{\circ} \mathrm{S}$, offshore Brazilian coast, there is a decrease in the 723 event density. The east portion of the Drake Passage also presents an increase, 724 but smaller than in the summer. African coast, between $30^{\circ} \mathrm{S}$ and $20^{\circ} \mathrm{S}$, present 725 a significant increase of cases.

726 The cyclone track density changes show an overall poleward increase in the 727 storm track associated with extreme waves (Fig. 10 and 11), but with a lack 728 of statistical significance. The differences are only significant in some points in 729 the middle of the South Atlantic for the tracks based on the $90^{t h}$ percentile 730 ( $95^{\text {th }}$ percentile is not shown since it does not have any significant change). 731 Despite that, the track changes are presented even to the NA to support further 732 discussion about other changes in cyclone-related wave occurrence. In the NA 733 (Fig. 10), the largest change occurs in the boreal winter (DJF), when the 734 track density increases on the USA coast. In the summer (JJA), the NA storm 735 track strength in the mid-to-eastern oceanic portion, which may be related 
to the increase in the cyclone-related wave density in the north portion of British Island. In the SA (Fig. 11), it is possible to observe a poleward shift of the associated cyclone tracks, similar to the reported general storm track behaviour in the last decades (e.g., Fyfe, 2003). However, in the SBR there is a slight increase in the cyclone track densities, probably indicating short duration cyclones with local effect.

Cyclone intensity based on the vorticity at $850 \mathrm{hPa}$ and displacement speed changes have spatially heterogeneous distribution denoting the challenge of feature distribution analysis. NA (Fig. 10c, d) shows a slight increase in the cyclone intensity in mid-latitudes in the boreal winter (DJF), while in the summer (JJA) a general negative sign prevails, except by the western European coast. In the SA (Fig. 11c, d), the winter (JJA) presents an increase in the associated cyclones in the middle of the basin. In the summer (DJF) there is a decrease of intensity in the middle and eastern portion of the domain while it is possible to see an intensification in the SBR region. The cyclone speed increases present an increase in the NA winter (DJF) in mid-latitudes near the western European coast and USC (Fig. 10e). In the summer (JJA) there is a significant slowdown of cyclones over the NNA region (Fig. 10f).

The SA cyclones associated with extreme waves present an increase in their displacement speed in the major part of the domain in both seasons (Fig. 11e, f), except between $30^{\circ} \mathrm{S}-20^{\circ} \mathrm{S}$ in the western portion of the basin. The overall increase in the cyclone speed may be related to the intensification of upper-level jets reported in some studies (e.g., Reboita et al, 2018). An important remark is that cyclones move according to the upper-level circulation rather than the surface winds (e.g., Hoskins and Hodges, 2002, 2019), which reflects the difference between cyclone intensity and speed distribution maps. A cyclone embedded in the upper-level jet tends to move faster than detached cyclones.

\section{Discussion}

\subsection{Extreme waves and the extratropical storm track}

The cyclone-related waves, defined here as the extreme wave regions directly associated with cyclones, present well-defined occurrence hot spots and the observed seasonal variability can be related to the storm track shifts. The seasonal variability is stronger in the NA, with much more events in the boreal winter (DJF) than in the summer (JJA). In the two ocean basins the cyclones associated with the extreme waves are generated preferentially in the western boundary, where the orography and warm ocean currents support their development (e.g., Grise et al, 2013; Gramcianinov et al, 2019). These cyclones travel to the east tilting poleward promoting extreme waves along the storm track and mainly in its downwind end, as reported by past studies (e.g., Ponce de León and Bettencourt, 2021; Ponce de León and Guedes Soares, 2021).

During the cyclone early stages, its development and intensification processes affect the positions of the fronts depending on the relative dominance of different air fluxes within the cyclones (e.g., warm and cold conveyor belts). 
783

784

785

786

787

788

789

790

791

792

793

794

795

796

797

798

799

800

801

802

803

804

805

806

807

808

809

810

811

812

813

814

815

816

817

818

819

820

821

822

823

824

825

826

827

828 (a) DJF | 90th

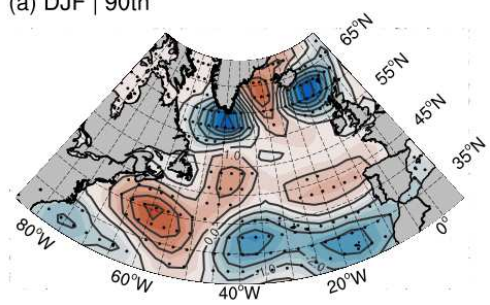

(b) JJA | 90th
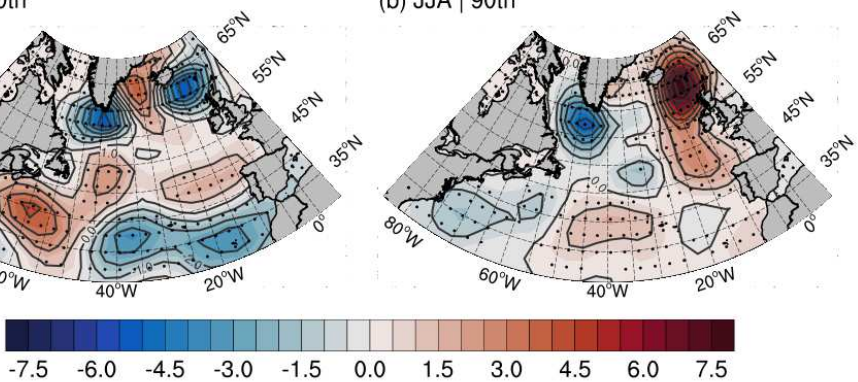

(c) DJF | 95th

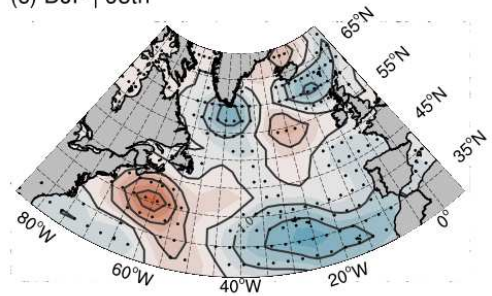

(d) JJA | 95th
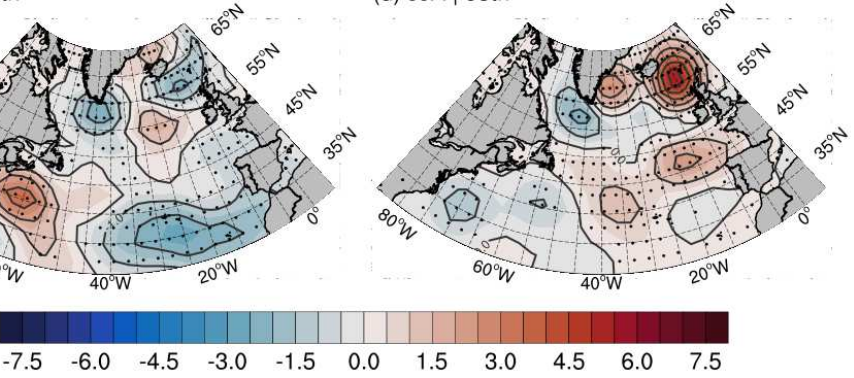

Fig. 8 Changes in the cyclone-related wave occurrence in the North Atlantic based on the $(\mathrm{a}, \mathrm{b}) 90^{t h}$ and $(\mathrm{c}, \mathrm{d}) 95^{\text {th }}$ percentiles for the (a,c) DJF and (b,d) JJA. Changes are computed based on the difference between 2020-2000 and 1979-1999 periods. Significant differences (p-value $<0.1$, t-test) are marked with black dots.

In this way, despite the cyclonic activity surrounding genesis regions, the lack of directional persistence of the winds and limited fetch size results in less extreme waves in the western sector of the domain. On the other hand, on the eastern portion where mature cyclones prevail, already fully developed, travelling eastward with more stable fetches relative to the cyclone displacement. The large size, intensity and stable structure of these advanced-stage cyclones allow the development of a large fetch with more stabilized wind direction when compared to the cyclogenetic regions (Fig. 7), resulting in higher waves (Fig. 6) and large occurrences of extremes in the eastern boundary of the domain, close to the exit of the storm track. The relation between the higher waves in the mid-eastern part of NA, the storm track and the large fetch provided by mature cyclones are in agreement with previous studies that established this location as wind-sea dominated (Stopa and Cheung, 2014) and highly influenced by extratropical cyclones (e.g., Ponce de León and Bettencourt, 2021). However, the north of the British Island, usually considered swell dominant due to the diminishing of the wind-swh correlation (Stopa and Cheung, 2014) and the presence of longer waves (Young, 1999), appears in the results as relevant to the cyclone-related wave climate, revealing also an important local forcing. 
(a) DJF | 90th

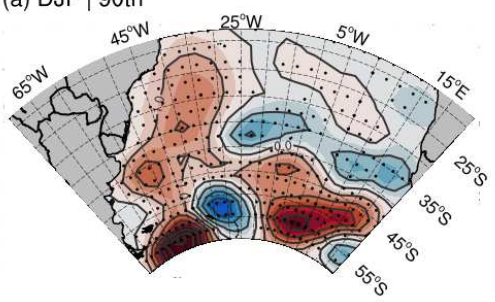

(b) JJA | 90th

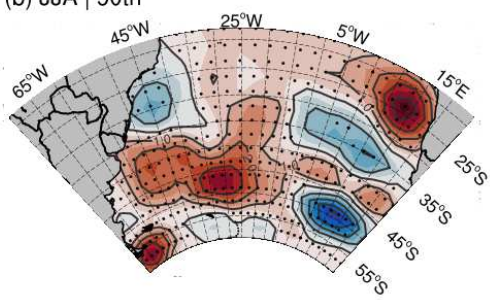

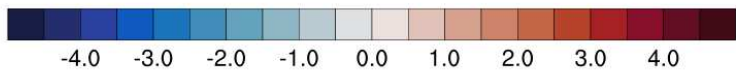

(c) DJF / 95th

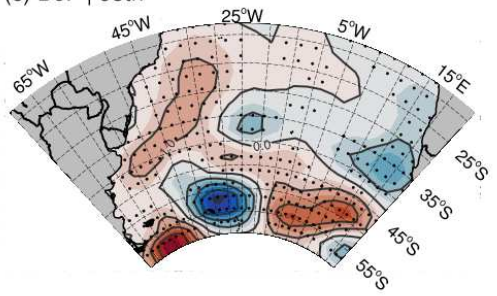

(d) JJA / 95th
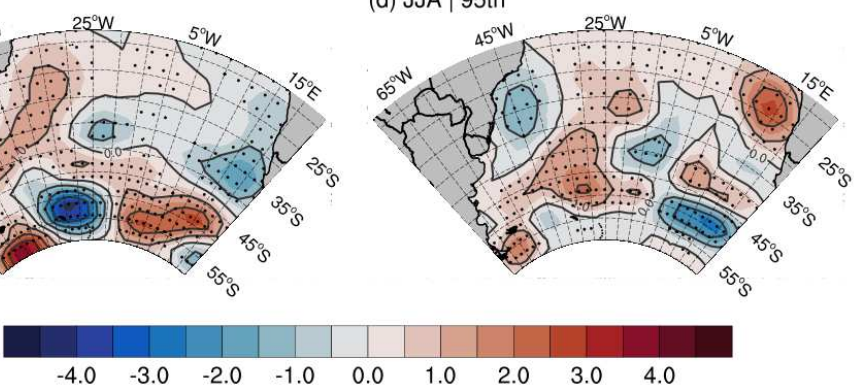

Fig. 9 Changes in the cyclone-related wave occurrence in the South Atlantic based on the (a,b) $90^{t h}$ and (c,d) $95^{t h}$ percentiles for the (a,c) DJF and (b,d) JJA. Changes are computed based on the difference between 2020-2000 and 1979-1999 periods. Significant differences (p-value $<0.1$, t-test) are marked with black dots.

The mid-oceanic genesis regions reported by Dacre and Gray (2009) for the NA and Gramcianinov et al (2019) for the SA play little influence on extreme wave generation due to the lack of time interaction with ocean surface, reinforcing the importance of cyclone lifecycle stage to extreme wave generation. One important point in the SA is that the LPB genesis region, which is responsible for producing most of the cyclone-related waves in the austral winter (JJA), also plays a big role in the summer (DJF) events, even not being very active in this season (e.g., Gan and Rao, 1991; Crespo et al, 2021). Another cyclogenetic region associated with wave extreme is the SBR, which is active in the austral summer (DJF) and where subtropical genesis and transitions between cyclone types are reported (e.g., Gozzo et al, 2014; da Rocha et al, 2019). The relation of SBR and LPB genesis with cyclone-related extreme waves within the SA domain can be related to the development of slower and/or stronger cyclones in subtropical latitudes, with the influence of high humidity income and warmer Brazilian Current (e.g., Gozzo et al, 2017).

The cyclones associated with extreme wave events present higher intensity regarding the vorticity and $10-\mathrm{m}$ wind speed (Fig. 4a-d). The direct relation between wind intensity is expected by the Hasselman relation, which shows that the wave growth directly correlates with the wind speed. The increase 
882

883

884

885

886

887

888

889

890

891

892

893

894

895

896

897

898

899

900

901

902

903

904

905

906

907

908

909

910

911

912

913

914

915

916

917

918

919

920

(a) DJF | 90th
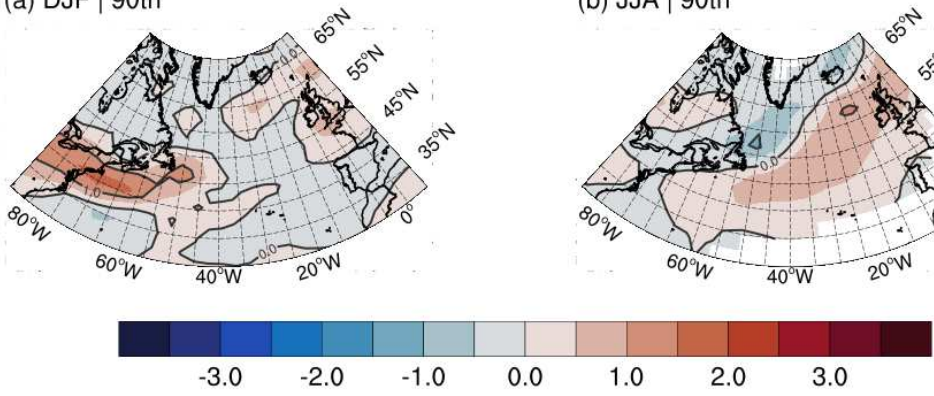

(c) DJF | 90th

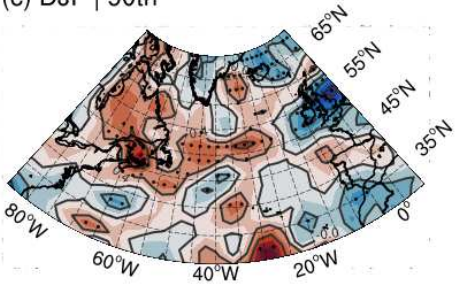

(d) JJA | 90th

(b) JJA | 90th

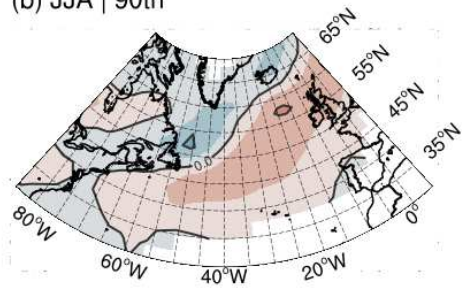

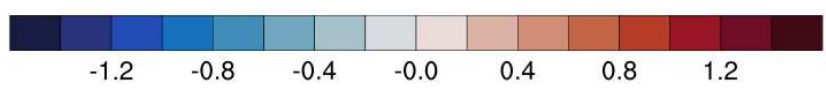

(e) DJF | 90th

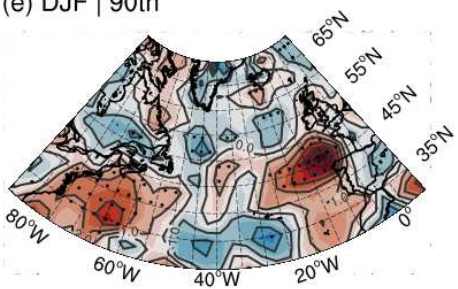

(f) JJA | 90th

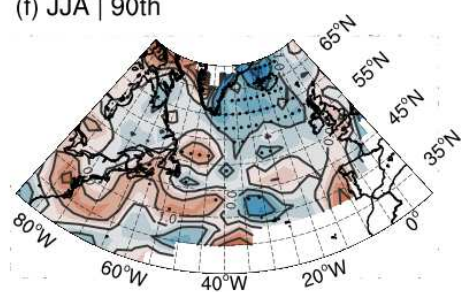

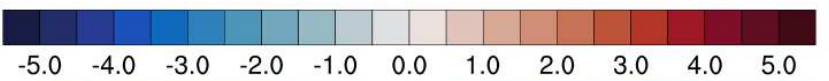

Fig. 10 Changes in the North Atlantic cyclone (a,b) track density (tracks per season per $\left.10^{6} \mathrm{~km}^{2}\right),(\mathrm{c}, \mathrm{d})$ vorticity at $850 \mathrm{hPa}\left(10^{5} \mathrm{~s}^{-1}\right)$, and speed $(\mathrm{m} / \mathrm{s})$ in the (a,c,e) DJF and $(\mathrm{b}, \mathrm{d}, \mathrm{f})$ JJA related to the $90^{\text {th }}$ percentile. Significant differences (p-value $<0.1$ ) are marked with black dots. Regions with track density smaller than 0.3 cyclones per season are not plotted. Black contoured lines have the double of shaded intervals.

of swh is also time-dependent, and the strong winds alone are not sufficient to fully develop extreme waves. Thus, the cyclone speed displacement also appears as a valuable parameter in our results, particularly in the regions outside the westerly belts in both hemispheres. In this location between $35^{\circ} \mathrm{S}$ and $20^{\circ} \mathrm{S}(\mathrm{SA})$ and $55^{\circ} \mathrm{N}$ and $70^{\circ} \mathrm{N}(\mathrm{NA})$ the cyclone's speed is generally smaller than the climatology (Fig. 4e-h), which impact the occurrence of the cyclone-related waves, either by producing higher waves or by elongating the duration of the events.

On average, extreme wave events tend to occur in the cold sector of the extratropical cyclone, to the westward of its centre, where it is located the cold 
(a) DJF | 90th

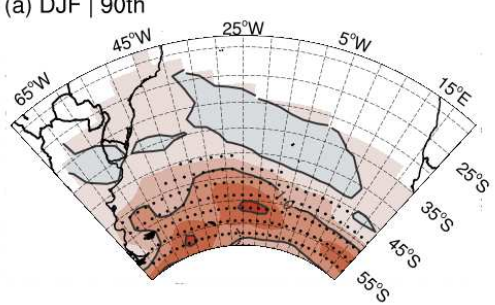

(b) JJA | 90th

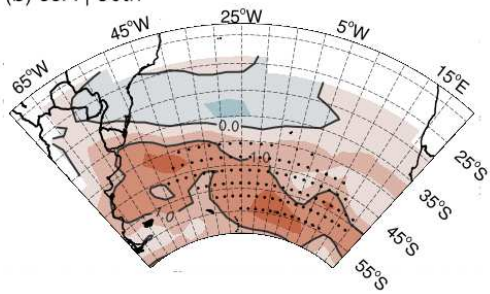

921

922

923

924

925

926

927

928

929

930

931

932

933

934

935

936

937

938

939

940

941

942

943

944

945

946

947

948

949

950

951

952

953

954

955

956

957

958

959

960

961

962

963

964

965

966 
967

968

969

970

971

972

973

974

975

976

977

978

979

980

981

982

983

984

985

986

987

988

989

990

991

992

993

994

995

996

997

998

999

1000

1001

1002

1003

1004

1005

1006

1007

1008

1009

1010

1011

1012

et al, 2020c; Ponce de León and Bettencourt, 2021) and it can lead to different perspectives of extreme wave generation within the extratropical cyclones. In agreement with Gramcianinov et al (2020c, 2021a), it is observed that the SBR presents a high influence of the warm conveyor belt in the summer (Fig. $7 \mathrm{~g}$ ), which may not generate waves that propagate towards the coast, but can severely influence the wave climate offshore, where there are oil exploitation and navigation activities.

\subsection{Changes in the cyclone-related waves}

The changes in the cyclone-related extreme wave occurrence cannot be fully explained by the storm track trends reflecting the complex mechanisms behind extreme wave climate patterns. The results showed a link between the changes in extreme wave occurrence and the cyclones characteristics, such as intensity and displacement speed; a summary of this relation is schematically presented in Fig. 12. The discussion of the changes are focused on the regions with high cyclone-related wave density (Fig. 1 and 2) and significant large changes (Fig. 8 and 9) according to the $90^{\text {th }}$ percentile analysis (significant results). In general, for both basins, there was an increase in the occurrence of extreme waves associated with cyclones, which is indicated by the changes in the number of cyclones (Table 1), storm track (Fig. 10a,b and 11a,b), and cyclone-related extreme waves (Fig. 8a,b and 9a,b), although the signal is not always statistically significant.

The NA present four regions of important changes in the cyclone-related extreme wave occurrence: eastern USA coast, Greenland, north of the British Islands, and west European coast. Despite the inclusion of the storm track changes in this discussion, more focus has been given to other parameters since the track density differences between the periods were not significant at any point in the NA. In the boreal winter (DJF), the strengthening of the storm track at the Eastern US coast may affect the extreme wave occurrence in this region and east-northeastward, including the west European coast between $40^{\circ} \mathrm{N}$ and $50^{\circ} \mathrm{N}$ (Fig. 8a). The changes showed that the cyclones developing in the USC and acting within $35^{\circ} \mathrm{N}$ and $50^{\circ} \mathrm{N}$ became stronger as well, which led to more extreme waves despite the observed increase in the cyclone speed over these regions. Further north in the domain, the East Greenland coast and British Islands are affected by the slight increase of the secondary storm track (not statistically significant). However, the former region presents an increase in wave occurrence due to the increase in cyclone intensity while the latter has weaker cyclones, presenting a decrease. Besides the cyclone intensity regulation, the summer pattern (JJA) showed a new element which was the effect of the decrease in the cyclone speed to the extreme wave occurrence. In the eastern Greenland coast and British Islands the cyclone intensity decrease was counterbalanced by a decrease of the displacement speed, elongating the cyclone's wind interaction with the ocean surface.

The same pattern can be extended to the SA, with its western portion presenting this counterbalance between intensity and speed in the summer 
(DJF). In the SA four regions are highlighted with important changes: the Southern Brazilian coast, western SA, Drake Passage, and southeastern SA. Changes in the SA storm track are statistically significant between $40^{\circ} \mathrm{S}$ and $55^{\circ} \mathrm{S}$, revealing an increase in the track density therein. The increase in the cyclonic activity in this band influences especially the Drake Passage and eastern portion of the domain, potentially increasing the extreme wave occurrence in these regions. The exception is the southeastern SA, where the extreme wave occurrence decreases due to the weakening of the cyclone acting in that region in the winter (JJA).

Besides the high amount of criteria used along this work to obtain robust results, some limitations must be held to the discussion above. The relations made between cyclone characteristics and extreme wave regions considered a distance of $10^{\circ}$ to $5^{\circ}$ between them. Despite the use of $1500 \mathrm{~km}\left(15^{\circ}\right)$ to link these features, the previous analysis showed that the distance is still within 200 - $700 \mathrm{~km}$ radius from the cyclone centre (Gramcianinov et al, 2021a), which allows the local interpretation of the results made in this work. However, the direct relation between the cyclone and wave distributions used can be set as a limitation of this work, since some fields present heterogeneous change signals, making challenging the interpretation (i.e., the scale of the change signal is smaller than $5^{\circ}$ ). To attenuate this problem, only some regions are discussed, highlighted by their significant signal, location, and extreme wave occurrence. Furthermore, it is important to remember that the method applied has removed the swell from the wave signal and the discussion considered only cyclone-related wave events, forced locally. Although some remote signals can still be retained, it is not dominant and does not influence the discussion.

\section{Conclusion}

The feature-based analysis applied in this work gave new insights into cyclonereinforce the findings in many extreme wave climatology studies (e.g., Vinoth and Young, 2011) and cyclone-related studies in the North Atlantic Ocean (Takbash et al, 2019; Ponce de León and Bettencourt, 2021; Gramcianinov et al, 2021b) and South Atlantic Ocean (Gramcianinov et al, 2020c, 2021a). The novelty of the present work relies on the direct link between cyclones and extreme wave events to add information and justify the observed distributions and trends of the extreme wave climate.

The hot-spot regions of cyclone-related waves occurrence resemble the locations that present high extreme statistics when using the traditional approach (i.e., extreme-value analyses, Vinoth and Young, 2011; Campos and Guedes Soares, 2016a,b; Campos et al, 2019; Takbash and Young, 2020), such as the downwind end of the storm track due to accumulation of cyclone related fetches and wind intensity. However, it is important to note that the western sector of both domains also presents relevant cases, associated with the intensification stages of cyclones. These cyclone-related waves occur close to cyclogenesis 
(a) DJF

1060

1061

1062

1063

1064

1065

1066

1067

1068

1069

1070

1071

1072

1073

1074

1075

1076 1077

1078

1079

1080

1081

1082

1083

1084

1085

1086

1087

1088

1089

1090

1091

1092

1093

1094

1095

1096

1097

1098

1099

1100

1101

1102

1103

1104

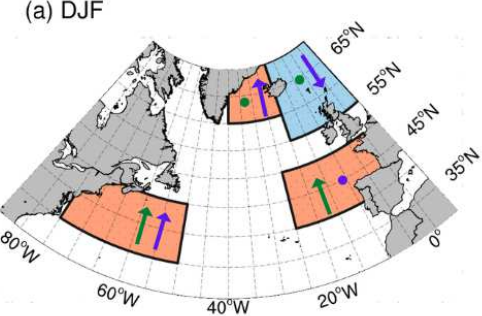

(c) DJF

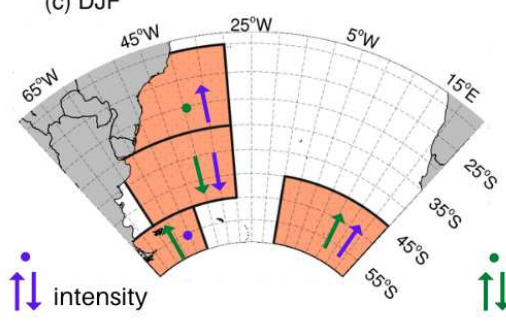

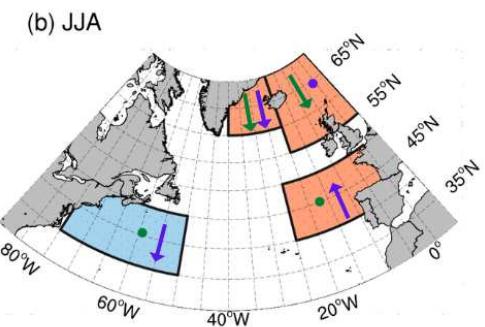

(d) JJA

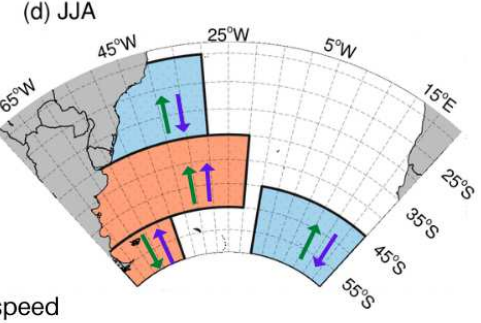

Fig. 12 Summary scheme of changes in the (a,b) North and (c,d) Atlantic cyclone-related extreme waves in present climate and their main driving mechanisms regarding storm track characteristics. The hot-spots are defined by back boxes filled with light red and blue for increase and decrease of extreme wave occurrence, respectively. Upward (downward) arrows indicate increase (decrease) of cyclone intensity (purple) and displacement speed (green) while the dots show non-significant signal.

regions in the western boundary of the basins, affecting off eastern South American and USA coasts - where such investigation cannot be neglected once these locations have high socio-economic value.

The cyclone lifecycle phase has been shown to play a big role in the extreme wave occurrence and swh distributions. In the early stages, strong winds are expected due to the cyclone development processes having enough intensity to generate extreme waves. However, the movements of the fronts in this phase contribute to a fast change of wind direction compromising the fetch persistence. On the other hand, in the middle of the storm track, cyclones in mature stages prevail, combining intensity and a more stable structure to generate a large fetch. Besides, cyclones associated with extreme waves are more intense, as expected, and present slower displacement speed when compared to the climatology, promoting extreme waves not just by the wind intensity but also due to the longer time of interaction between this wind and the ocean surface.

Considering 42 years, the changes in the distribution of cyclone-related events and cyclones characteristics are linked in different ways, and they result not only from the storm track position but also from a combination of factors. It is expected that changes in the storm track orientation play a big role in the cyclone-related wave climate. However, the results do not present significant changes in the storm track in most of the domains. Instead, the balance between the cyclone speed and intensity dictated the extreme wave changes. The local increase in cyclone intensity leads to an increase in the 
wave extremes, but the decrease of intensity does not necessarily result in a decrease of the waves (Fig. 12). In this situation, the cyclone speed behaves as a modulator: if the cyclones are somewhere slower, they counterbalance the weakness by increasing the time of interaction between wind and ocean surface, i.e., wind persistence, increasing or elongating extreme wave events.

Despite the relatively small changes in cyclone-related extreme waves (up to 7.5 occurrences per month per area), the impact on the ocean and coastal activities are considerable, especially considering the 42 years time interval. The statistics based on individual events applied in this work provide valuable information to assess trends and future changes, giving more insights about changes in the weather systems rather than overall climate change patterns.

Acknowledgements. This work is part of the project "Extreme wind and wave modelling and statistics in the Atlantic Ocean" (EXWAV) funded by the São Paulo Research Foundation (FAPESP) grant \#2018/08057-5 and by the Portuguese Foundation for Science and Technology (Fundação para a Ciência e Tecnologia - FCT) under contract PTDC/EAM-OCE/31325/2017 RD0504. This work contributes to the Strategic Research Plan of the Centre for Marine Technology and Ocean Engineering (CENTEC), which is financed by the Portuguese Foundation for Science and Technology (Fundação para a Ciência e Tecnologia - FCT) under contract UIDB/UIDP/00134/2020. C.B.G. holds a FAPESP postdoc scholarship grant \#2020/01416-0. The authors would like to acknowledge the ECMWF for providing the atmospheric and wave data for the study, as well as Dr. Kevin Hodges for providing the TRACK code. The ERA5 products were generated using Copernicus Climate Change Service Information [2019]. This study used the high-performance computing resources of the SDumont supercomputer (http://sdumont.lncc.br), which is provided by the National Laboratory for Scientific Computing (LNCC/MCTI, Brazil).

\section{Declarations}

Funding. $\quad$ grant \#2018/08057-5, São Paulo Research Foundation (FAPESP); grant \#2020/01416-0, São Paulo Research Foundation (FAPESP); contract PTDC/EAM-OCE/31325/2017, Fundação para a Ciência e Tecnologia - FCT; contract UIDB/UIDP/00134/2020, Fundação para a Ciência e Tecnologia FCT.

Availability of data and material. The ERA5 products were obtained with Copernicus Climate Change Service (C3S) (2017) (https://cds.climate.copernicus.eu/, last access: June 2021). The Cyclone tracks used in this study are available at "Atlantic extratropical cyclone tracks databases" (https://data.mendeley.com/datasets/kwcvfr52hp/5; Gramcianinov et al, 2020b). The cyclone track associated with extreme wave events obtained in this study can be shared upon request by email.

Code availability. The codes used in Section 3.3 can be shared upon request by email. 
1151 Authors' contribution. CBG: Conceptualization, Formal analysis, 1152 Methodology, Visualization, Writing - original draft. RC and RMC: Con1153 ceptualization, Methodology, Writing - review \& editing. PLSD and CGS: 1154 Writing - review \& editing, Supervision.

1155

1156

Conflict of interest. The authors declare that they have no conflict of 1157

1158

\section{References}

1160

1161

1162

1163

1164

1165

1166

1167

1168

1169

1170

1171

1172

1173

1174

1175

1176

1177

1178

1179

1180

1181

1182

1183

1184

1185

1186

1187

1188

1189

1190

1191

1192

1193

1194

1195

1196

Alves JHG (2006) Numerical modeling of ocean swell contributions to the global wind-wave climate. Ocean Model 11(1-2):98-122. https://doi.org/10. 1016/j.ocemod.2004.11.007

Ardhuin F, Orfila A (2018) Wind Waves. New Front Oper Oceanogr pp 393422. https://doi.org/10.17125/gov2018.ch14

Ardhuin F, Chapron B, Collard F (2009) Observation of swell dissipation across oceans. Geophys Res Lett 36(6):1-5. https://doi.org/10.1029/ 2008GL037030, https://arxiv.org/abs/0809.2497

Bell RJ, Gray SL, Jones OP (2017) North Atlantic storm driving of extreme wave heights in the North Sea. J Geophys Res Ocean 122(4):3253-3268. https://doi.org/10.1002/2016JC012501

Belmonte Rivas M, Stoffelen A (2019) Characterizing ERA-Interim and ERA5 surface wind biases using ASCAT. Ocean Sci 15(3):831-852. https://doi. org/10.5194/os-15-831-2019

Bengtsson L, Hodges KI, Keenlyside N (2009) Will extratropical storms intensify in a warmer climate? J Clim 22(9):2276-2301. https://doi.org/10.1175/ 2008JCLI2678.1, https://arxiv.org/abs/9501047 [cond-mat]

Bernardino M, Gonçalves M, Guedes Soares C (2021) Marine climate projections toward the end of the twenty-first century in the north atlantic. Journal of Offshore Mechanics and Arctic Engineering 143(6). https://doi. org $/ 10.1115 / 1.4050698$

Bitner-Gregersen EM, Vanem E, Gramstad O, et al (2018) Climate change and safe design of ship structures. Ocean Engineering 149:226-237. https: //doi.org/10.1016/j.oceaneng.2017.12.023

Caires S, Sterl A (2005) 100-year return value estimates for ocean wind speed and significant wave height from the ERA-40 data. J Clim 18(7):1032-1048. https://doi.org/10.1175/JCLI-3312.1

Campos RM, Guedes Soares C (2016a) Comparison and assessment of three wave hindcasts in the North Atlantic Ocean. Journal of Operational Oceanography 9(1):26-44. https://doi.org/10.1080/1755876x.2016.1200249 Campos RM, Guedes Soares C (2016b) Comparison of HIPOCAS and ERA wind and wave reanalyses in the North Atlantic Ocean. Ocean Engineering 112:320-334. https://doi.org/10.1016/j.oceaneng.2015.12.028

Campos RM, Alves JH, Guedes Soares C, et al (2018) Extreme wind-wave modeling and analysis in the South Atlantic ocean. Ocean Model 124(August 2017):75-93. https://doi.org/10.1016/j.ocemod.2018.02.002 
Campos RM, Guedes Soares C, Alves JH, et al (2019) Regional long-term extreme wave analysis using hindcast data from the South Atlantic Ocean. Ocean Eng 179(March):202-212. https://doi.org/10.1016/j.oceaneng.2019. 03.023

Campos RM, D'Agostini A, França BRL, et al (2020) Extreme Wind and Wave Predictability From Operational Forecasts at the Drake Passage. Journal of Offshore Mechanics and Arctic Engineering 143(2). https://doi.org/10. $1115 / 1.4048151$

Catto JL, Ackerley D, Booth JF, et al (2019) The Future of Midlatitude Cyclones. Curr Clim Chang Reports 5(4):407-420. https://doi.org/10.1007/ s40641-019-00149-4

Chen G, Chapron B, Ezraty R, et al (2002) A global view of swell and wind sea climate in the ocean by satellite altimeter and scatterometer. J Atmos Ocean Technol 19(11):1849-1859. https://doi.org/10.1175/1520-0426(2002) 019<1849:AGVOSA $>2.0 . \mathrm{CO} ; 2$

Copernicus Climate Change Service (C3S) (2017) ERA5: Fifth generation of ECMWF atmospheric reanalyses of the global climate. Copernicus Climate Change Service Climate Data Store (CDS), URL https://cds.climate. copernicus.eu/cdsapp\#!/home, last access: 20 Jan. 2021

Crespo NM, da Rocha RP, Sprenger M, et al (2021) A potential vorticity perspective on cyclogenesis over centre-eastern South America. International Journal of Climatology 41(1):663-678. https://doi.org/https://doi.org/10. $1002 /$ joc. 6644

da Rocha RP, Reboita MS, Gozzo LF, et al (2019) Subtropical cyclones over the oceanic basins: a review. Ann N Y Acad Sci 1436(1):138-156. https: //doi.org/10.1111/nyas.13927

Dacre HF, Gray SL (2009) The spatial distribution and evolution characteristics of North Atlantic cyclones. Mon Weather Rev 137(1):99-115. https: //doi.org/10.1175/2008MWR2491.1

de Jesus EM, da Rocha RP, Crespo NM, et al (2020) Multi-model climate projections of the main cyclogenesis hot-spots and associated winds over the eastern coast of south america. Climate Dynamics 56(1-2):537-557. https: //doi.org/10.1007/s00382-020-05490-1

Dobrynin M, Murawsky J, Yang S (2012) Evolution of the global wind wave climate in CMIP5 experiments. Geophys Res Lett 39(17):2-7. https://doi. org/10.1029/2012GL052843

Fyfe JC (2003) Extratropical Southern Hemisphere cyclones: Harbingers of climate change? J Clim 16(17):2802-2805. https://doi.org/10.1175/ 1520-0442(2003)016<2802:ESHCHO $>2.0 . \mathrm{CO} ; 2$

Gan MA, Rao VB (1991) Surface Cyclogenesis over South America. Mon Weather Rev 119(5):1293-1302. https://doi.org/10.1175/1520-0493(1991) 119<1293:SCOSA $>2.0 . \mathrm{CO} ; 2$

Geng Q, Sugi M (2003) Possible change of extratropical cyclone activity due to enhanced greenhouse gases and sulfate aerosols - Study with a high-resolution AGCM. J Clim 16(13):2262-2274. https://doi.org/10.1175/ 


\section{1520-0442(2003)16<2262:PCOECA $\rangle 2.0 . \mathrm{CO} ; 2$}

1244 Gozzo LF, da Rocha RP, Reboita MS, et al (2014) Subtropical cyclones over

1245 the southwestern South Atlantic: Climatological aspects and case study. J

1246 Clim 27(22):8543-8562. https://doi.org/10.1175/JCLI-D-14-00149.1

1247 Gozzo LF, da Rocha RP, Gimeno L, et al (2017) Climatology and numerical

1248 case study of moisture sources associated with subtropical cyclogenesis over

1249 the southwestern Atlantic Ocean. J Geophys Res 122(11):5636-5653. https:

1250 //doi.org/10.1002/2016JD025764

1251 Gramcianinov CB, Hodges KI, Camargo R (2019) The properties and gene-

1252 sis environments of South Atlantic cyclones. Clim Dyn 53(7-8):4115-4140.

1253 https://doi.org/10.1007/s00382-019-04778-1

1254 Gramcianinov CB, Campos RM, de Camargo R, et al (2020a) Analysis of

1255 Atlantic extratropical storm tracks characteristics in 41 years of ERA5 and

1256 CFSR/CFSv2 databases. Ocean Eng 216:108,111. https://doi.org/10.1016/

1257 j.oceaneng.2020.108111

1258 Gramcianinov CB, Campos RM, de Camargo R, et al (2020b) Atlantic extra-

1259 tropical cyclone tracks in 41 years of ERA5 and CFSR/CFSv2 databases.

1260 Mendeley Data V4. https://doi.org/10.17632/kwcvfr52hp.4

1261 Gramcianinov CB, Campos RM, Guedes Soares C, et al (2020c) Extreme

1262 waves generated by cyclonic winds in the western portion of the South

1263 Atlantic Ocean. Ocean Eng 213(1):107,745. https://doi.org/10.1016/j.

1264 oceaneng.2020.107745

1265 Gramcianinov CB, Campos RM, de Camargo R, et al (2021a) Relation between

1266 cyclone evolution and fetch associated with extreme wave events in the South

1267 Atlantic Ocean. J Offshore Mech Arct Eng 2A-2020:1-27. https://doi.org/

1268 10.1115/1.4051038

1269 Gramcianinov CB, Campos RM, Guedes Soares C, et al (2021b) Distribution

1270 and characteristics of extreme waves generated by extratropical cyclones in

1271 the North Atlantic Ocean. In: Guedes Soares C, Santos TA (eds) Develop-

1272 ments in Maritime Technology and Engineering. Taylor and Francis, London,

1273 UK, p 797-804

1274 Grise KM, Son SW, Gyakum JR (2013) Intraseasonal and interannual variabil-

1275 ity in north american storm tracks and its relationship to equatorial pacific

1276 variability. Mon Weather Rev 141(10):3610-3625. https://doi.org/10.1175/

1277 MWR-D-12-00322.1

1278 Guedes Soares C (1984) Representation of double-peaked sea wave spectra. 1279 Ocean Engineering 11(2):185-207. https://doi.org/10.1016/0029-8018(84)

1280 90019-2

1281 Hasselmann K, Barnett TP, Bouws E, et al (1973) Measurements of wind1282 wave growth and swell decay during the Joint North Sea wave project 1283 (JONSWAP). Deutches Hydrographisches Institut Zeit (A8):1-95

1284 Hersbach H, Bell B, Berrisford P, et al (2020) The ERA5 global reanalysis. Q 1285 J R Meteorol Soc 146(730):1999-2049. https://doi.org/10.1002/qj.3803

1286 Hodges KI (1994) A General Method for Tracking Analysis and Its Application 1287 to Meteorological Data. Mon Weather Rev 122(11):2573-2586. https://doi. 
org/10.1175/1520-0493(1994)122〈2573:AGMFTA $>2.0 . C O ; 2$

Hodges KI (1995) Feature Tracking on the Unit Sphere. Mon Weather Rev 123(12):3458-3465. https://doi.org/10.1175/1520-0493(1995)123/3458: FTOTUS $>2.0 . \mathrm{CO} ; 2$

Hodges KI (1996) Spherical Nonparametric Estimators Applied to the UGAMP Model Integration for AMIP. Mon Weather Rev 124(12):29142932. https://doi.org/10.1175/1520-0493(1996)124〈2914:SNEATT $\rangle 2.0 . C O$; 2

Hodges KI (1999) Adaptative Constraints for Feature Tracking. Mon Weather Rev 127:1362-1373. https://doi.org/10.4324/9781315658032

Hodges KI (2008) Confidence intervals and significance tests for spherical data derived from feature tracking. Monthly Weather Review 136(5):1758-1777. https://doi.org/10.1175/2007MWR2299.1

Hoskins BJ, Hodges KI (2002) New Perspectives on the Northern Hemisphere Winter Storm Tracks. J Atmos Sci 59(6):1041-1061. https://doi.org/10. 1175/1520-0469(2002)059〈1041:NPOTNH $\rangle 2.0 . \mathrm{CO} ; 2$

Hoskins BJ, Hodges KI (2005) A New Perspective on Southern Hemisphere Storm Tracks. J Clim 18(20):4108-4129. https://doi.org/10.1175/JCLI3570. 1, https://arxiv.org/abs/joc.1492 [10.1002]

Hoskins BJ, Hodges KI (2019) The annual cycle of Northern Hemisphere storm tracks. Part I: Seasons. J Clim 32(6):1743-1760. https://doi.org/10.1175/ JCLI-D-17-0870.1

1297

1298

1299

1300

1301

1302

1303

1304

1305

1306

1307

1308

1309

1310

Kita Y, Waseda T, Webb A (2018) Development of waves under explosive cyclones in the Northwestern Pacific. Ocean Dyn 68(10):1403-1418. https: //doi.org/10.1007/s10236-018-1195-z

1312

1313

Lambert SJ, Fyfe JC (2006) Changes in winter cyclone frequencies and strengths simulated in enhanced greenhouse warming experiments: Results from the models participating in the IPCC diagnostic exercise. Clim Dyn 26(7-8):713-728. https://doi.org/10.1007/s00382-006-0110-3

1315

1316

1317

Lemos G, Semedo A, Dobrynin M, et al (2019) Mid-twenty-first century global wave climate projections: Results from a dynamic CMIP5 based ensemble. Glob Planet Change 172:69-87. https://doi.org/10.1016/j.gloplacha.2018. 09.011

Lim EP, Simmonds I (2002) Explosive Cyclone Development in the Southern Hemisphere and a Comparison with Northern Hemisphere Events. Monthly Weather Review 130(9):2188-2209. https://doi.org/10. 1175/1520-0493(2002)130<2188:ecdits $>2.0 . c 0 ; 2$

1318

1319

1320

1321

1322

1323

1324

1325

Meucci A, Young IR, Hemer M, et al (2020) Projected 21st century changes in extreme wind-wave events. Sci Adv 6(24):eaaz7295. https://doi.org/10. 1126/sciadv.aaz7295

Pezza AB, Ambrizzi T (2003) Variability of Southern Hemisphere Cyclone and Anticyclone Behavior: Further Analysis. J Clim 16:1075-1083. https: //doi.org/10.1175/1520-0442(2003)016<1075:VOSHCA >2.0.CO;2

1326

1327

1328

1329

1330

1331

Ponce de León S, Bettencourt J (2021) Composite analysis of North Atlantic 
1335 Res 68(2):762-772. https://doi.org/10.1016/j.asr.2019.07.021

1336 Ponce de León S, Guedes Soares C (2014) Extreme wave parameters under

1337 North Atlantic extratropical cyclones. Ocean Modelling 81:78-88. https://

1338 doi.org/10.1016/j.ocemod.2014.07.005

1339 Ponce de León S, Guedes Soares C (2015) Hindcast of extreme sea states in

1340 North Atlantic extratropical storms. Ocean Dynamics 65(2):241-254. https:

1341 //doi.org/10.1007/s10236-014-0794-6

1342 Ponce de León S, Guedes Soares C (2021) Numerical modelling of the effects

1343 of the gulf stream on the wave characteristics. Journal of Marine Science

1344 and Engineering 9(1):42. https://doi.org/10.3390/jmse9010042

1345 Rapizo H, Babanin AV, Schulz E, et al (2015) Observation of wind-waves

1346 from a moored buoy in the Southern Ocean. Ocean Dyn 65(9-10):1275-1288.

1347 https://doi.org/10.1007/s10236-015-0873-3

1348 Reboita MS, da Rocha RP, Ambrizzi T, et al (2015) Trend and telecon-

1349 nection patterns in the climatology of extratropical cyclones over the

1350 Southern Hemisphere. Clim Dyn 45(7-8):1929-1944. https://doi.org/10.

1351 1007/s00382-014-2447-3

1352 Reboita MS, da Rocha RP, de Souza MR, et al (2018) Extratropical cyclones

1353 over the southwestern South Atlantic Ocean: HadGEM2-ES and RegCM4

1354 projections. Int J Climatol 38(6):2866-2879. https://doi.org/10.1002/joc.

$1355 \quad 5468$

1356 Reboita MS, Reale M, da Rocha RP, et al (2020) Future changes in the win-

1357 tertime cyclonic activity over the CORDEX-CORE Southern Hemisphere

1358 domains in a multi-model approach. Climate Dynamics 57(5-6):1533-

1359 1549. https://doi.org/10.1007/s00382-020-05317-z, URL https://doi.org/

$136010.1007 / \mathrm{s} 00382-020-05317-\mathrm{z}$

1361 Reboita MS, Crespo NM, Torres JA, et al (2021) Future changes in

1362 winter explosive cyclones over the Southern Hemisphere domains from

1363 the CORDEX-CORE ensemble. Clim Dyn (1). https://doi.org/10.1007/

1364 s00382-021-05867-w

1365 da Rocha RP, Sugahara S, da Silveira RB (2004) Sea Waves Generated by 1366 Extratropical Cyclones in the South Atlantic Ocean: Hindcast and Val1367 idation against Altimeter Data. Weather and Forecasting 19(2):398-410.

1368 https://doi.org/10.1175/1520-0434(2004)019/0398:swgbec $\rangle 2.0 . c 0 ; 2$

1369 Sanders F, Gyakum JR (1980) Synoptic-dynamic climatology of the "bomb".

1370 Monthly Weather Review 108(10):1589-1606. https://doi.org/10.1175/

1371 1520-0493(1980)108<1589:sdcot $\rangle 2.0$. co;2

1372 Simmonds I, Keay K (2000) Mean Southern Hemisphere extratropical cyclone 1373 behavior in the 40-year NCEP-NCAR reanalysis. J Clim 13(5):873-885.

1374 https://doi.org/10.1175/1520-0442(2000)013〈0873:MSHECB $\rangle$ 2.0.CO;2

1375 Sinclair MR (1994) An objective cyclone climatology for the Southern 1376 Hemisphere. https://doi.org/10.1175/1520-0493(1994)122/2239:AOCCFT $\rangle$ 1377 2.0.CO;2

1378 Stopa JE, Cheung KF (2014) Intercomparison of wind and wave data from 1379 the ECMWF Reanalysis Interim and the NCEP Climate Forecast System 
Reanalysis. Ocean Model 75:65-83. https://doi.org/10.1016/j.ocemod.2013. 12.006

Takbash A, Young IR (2020) Long-term and seasonal trends in global wave height extremes derived from ERA-5 reanalysis data. J Mar Sci Eng 8(12):116. https://doi.org/10.3390/jmse8121015

1383

1384

1385

Takbash A, Young IR, Breivik Ø (2019) Global wind speed and wave height

1386 extremes derived from long-duration satellite records. J Clim 32(1):109-126. https://doi.org/10.1175/JCLI-D-18-0520.1

1387

1388

Ulbrich U, Leckebusch GC, Pinto JG (2009) Extra-tropical cyclones in the 1389 present and future climate: A review. Theor Appl Climatol 96(1-2):117-131. https://doi.org/10.1007/s00704-008-0083-8, https://arxiv.org/abs/9605103 $[\mathrm{cs}]$

Vettor R, Guedes Soares C (2020) A global view on bimodal wave spectra 1393 and crossing seas from ERA-interim. Ocean Engineering 210:107,439. https: //doi.org/10.1016/j.oceaneng.2020.107439

Vinoth J, Young IR (2011) Global Estimates of Extreme Wind Speed and Wave 1395 Height. J Clim 24(6):1647-1665. https://doi.org/10.1175/2010JCLI3680.1 1396 1397

Wang XL, Swail VR, Zwiers FW (2006) Climatology and changes of extratropical cyclone activity: Comparison of ERA-40 with NCEP-NCAR reanalysis for 1958-2001. J Clim 19(13):3145-3166. https://doi.org/10.1175/JCLI3781. 1

Young IR (1999) Seasonal variability of the global ocean wind and wave climate. Int J Climatol 19(9):931-950. https://doi.org/10.1002/(SICI) 1097-0088(199907)19:9/931::AID-JOC412〉3.0.CO;2-O

Young IR, Ribal A (2019) Multiplatform evaluation of global trends in wind 1405 speed and wave height. Science (80- ) 364(6440):548-552. https://doi.org/ 10.1126/science.aav9527

1406 

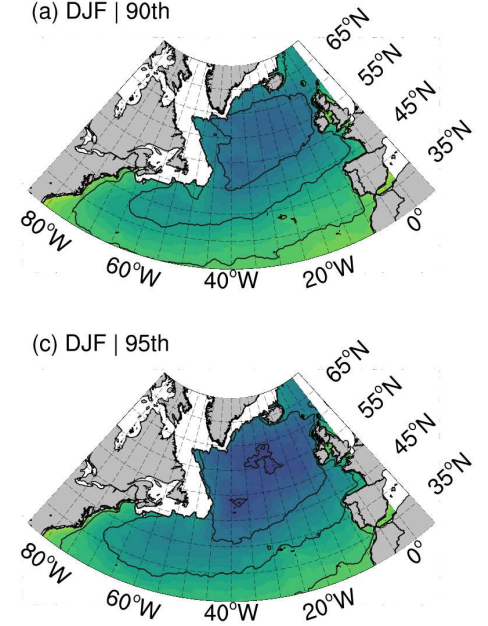

1450

1451

1452

1453

1454

1455

1456

1457

1458

1459

1460

1461

1462

1463 Fig. A1 The swh thresholds obtained based on the (a,b) $90^{t h},(\mathrm{c}, \mathrm{d}) 95^{t h}$, and (e,f) $99^{t h}$ 1464 percentiles for the North Atlantic basins in the (a,c,e) DJF and (b,d,f) JJA. Black contours 1465 are in $2 \mathrm{~m}$ intervals.

1466

1467

1468

1469

1470

1471

1472 (a) DJF | 90th

(c) DJF | 95th
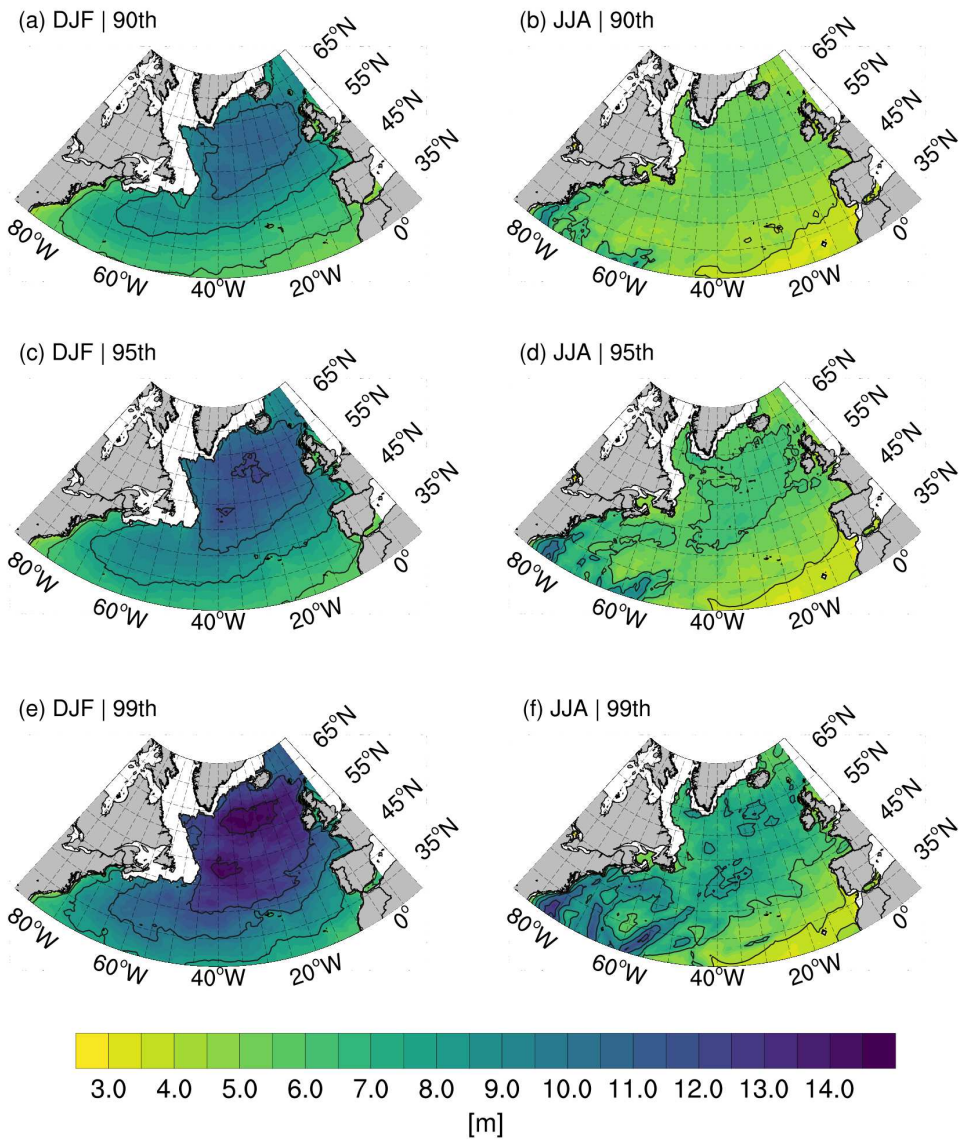


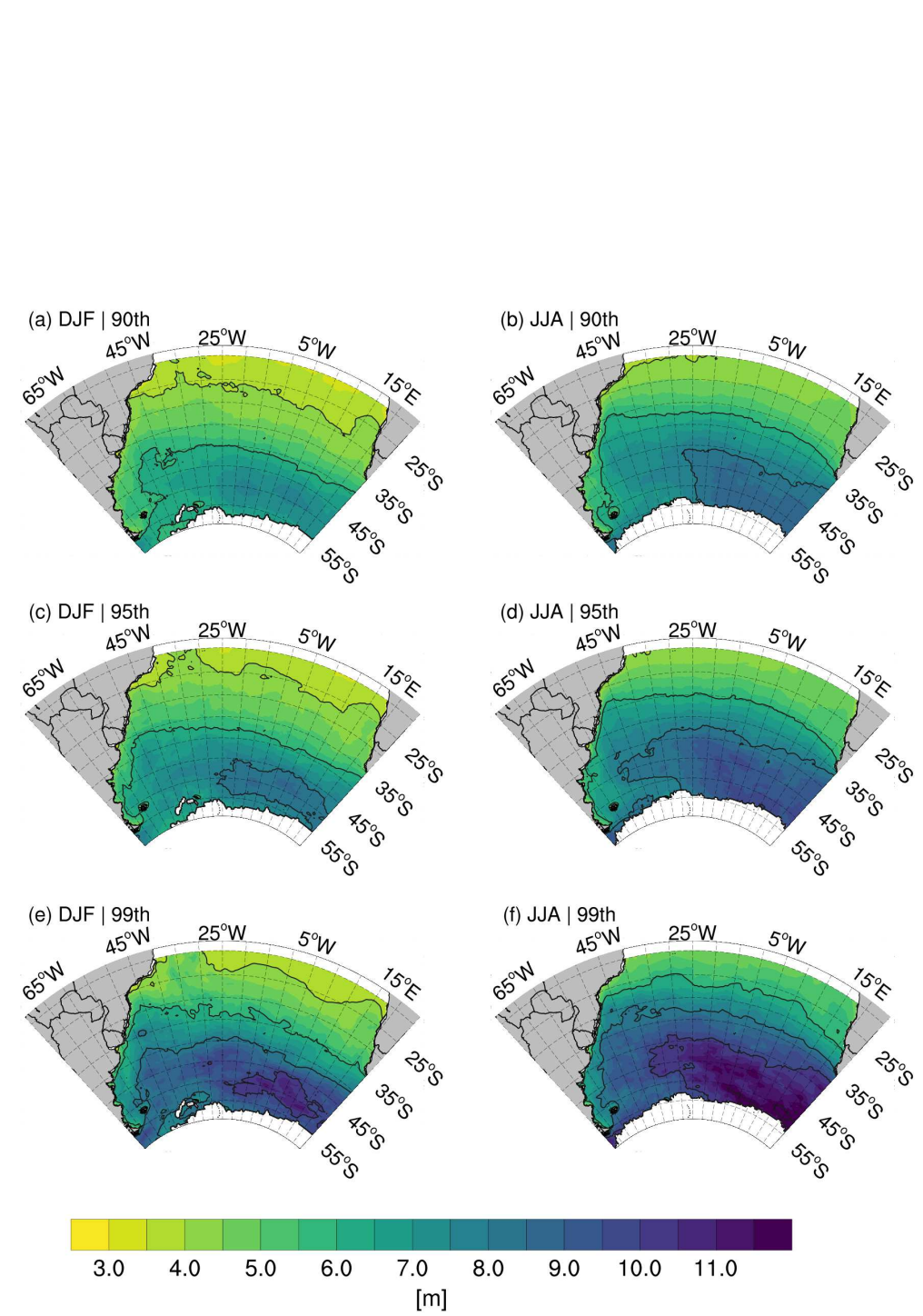

Fig. A2 The swh thresholds obtained based on the (a,b) $90^{t h},(\mathrm{c}, \mathrm{d}) 95^{\text {th }}$, and (e,f) $99^{\text {th }}$ percentiles for the South Atlantic basins in the (a,c,e) DJF and (b,d,f) JJA. Black contours are in $2 \mathrm{~m}$ intervals. 
34 Impact of extratropical cyclones on the extreme wave trends

1519

1520

1521

1522

1523

1524

1525

1526

1527

1528

1529

1530

1531

1532

1533

1534

1535

1536

1537

1538

1539

1540

1541

1542

1543

1544

1545

1546

1547

1548

1549

(a) DJF | 90th

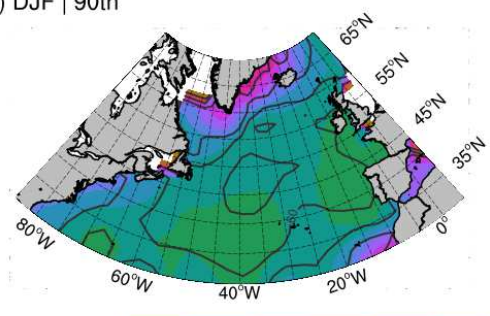

(b) JJA | 90th

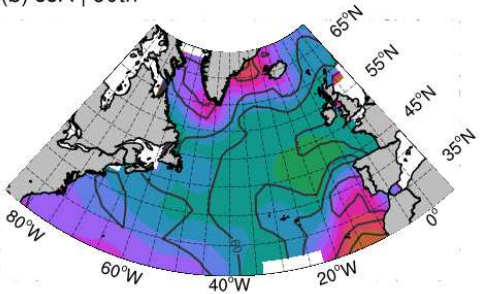

$210 \quad 240 \quad 270 \quad 300 \quad 330$

1550

Fig. A3 Distribution maps of the mean $10-\mathrm{m}$ wind direction of the $90^{t h}$ cases for the 1551 (a,b) NA and (c,d) SA in the (a,c) DJF and (b,d) JJA. The contour lines are the standard 1552 deviation in $30^{\circ}$ intervals.

1553

1554

1555

1556

1557

1558

1559

1560

1561

1562

1563

1564

(c) DJF | 90th

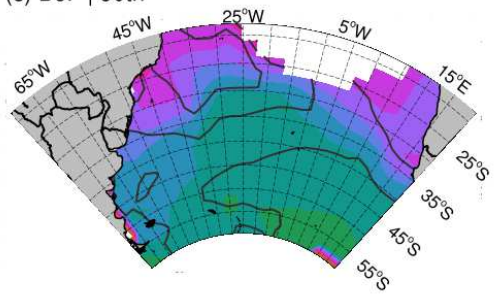

(d) JJA $\mid 90$ th

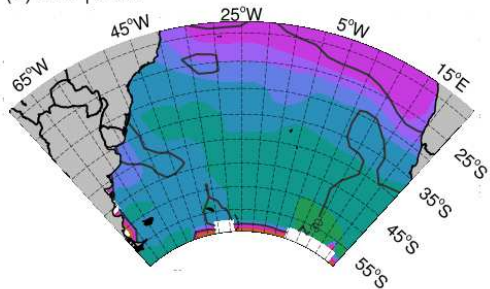

